\title{
Best Practices for Communication between Client and Vendor in IT Outsourcing Projects
}

\author{
Ravi Sharma, SR Apoorva, Venkata Madireddy, and Varun Jain \\ Wee Kim Wee School of Communication \& Information, \\ Nanyang Technological University, Singapore
}

\author{
asrsharma@ntu.edu.sg; Apoorva.sr@gmail.com; \\ venkat.madireddy@gmail.com; jain0003@ntu.edu.sg
}

\begin{abstract}
It has been reported that outsourcing specialist knowledge work can enable business excellence by enhancing business competitiveness, economic value added service, quality, and market branding. Much of this may be supported by seamless technical communication flows between the vendors and clients of an outsourcing project. However, the potential loss of confidentiality, authority, and security are key factors organizations take into consideration before venturing into outsourcing. Developing an information communication platform which promotes a secure knowledge exchange culture in an environment conducive to trust is fundamental to mitigate these information risk factors. The empirical study reported in this paper investigated the central postulate that effective management of technical communication at every stage of executing an IT outsourcing contract reduces associated risks and establishes trust in an outsourcing relationship. The objective of the study was to provide knowledge managers with an insight into the effectiveness of communication flows for various outsourcing activities in order to support knowledge mobilization for effective service delivery. The field research was conducted through a survey of industry practitioners from vendor and client organizations with a sample size of $70+$ respondents from $20+$ organizations, about an equal number of clients and vendors. It is the intended contribution of this work to prescribe a socio-technical platform for professional technical communications between clients and vendors of outsourcing services that effectively manages information risks and the notion of trust arising from the project life-cycle.
\end{abstract}

Keywords: IT Outsourcing, Project Management, Trust; Risk, Technical Communication, Communication Channels and Media, Knowledge Flow and Information Flow.

\section{Introduction}

With the usage of information and communication technologies (ICT) now considered routine and commoditized by most organizations, such auxiliary or non-core functionalities are better

Material published as part of this publication, either on-line or in print, is copyrighted by the Informing Science Institute. Permission to make digital or paper copy of part or all of these works for personal or classroom use is granted without fee provided that the copies are not made or distributed for profit or commercial advantage AND that copies 1) bear this notice in full and 2) give the full citation on the first page. It is permissible to abstract these works so long as credit is given. To copy in all other cases or to republish or to post on a server or to redistribute to lists requires specific permission and payment of a fee. Contact Publisher@InformingScience.org to request redistribution permission. managed by the practice of outsourcing. Outsourcing has often provided positive results for companies, with most experiencing recurring cost cutting (Hines, 2005), time saving (DiRomualdo \& Gurbaxani, 1998), and improved performance (Barthelemy, 2001; Constantinescu, 2005) in their operations due to a combination of having access to scarce expertise as well as taking the associated costs off the balance sheet. In addition, 
the practice of outsourcing has enabled organizations to foster innovation by focusing on core competencies (Huff, 1991), higher quality (Turban, McLean, \& Wetherbe, 2002), provide better service, and increase their competitive advantage (Power, Bonifazi, \& Desouza, 2004). Thus, outsourcing has gained wide acceptance (Mullin, 1996) and over the last decade has seen widespread developments in order to meet an organization's information technology needs (Dibbern, Goles, Hirschheim, \& Jayatilaka, 2004).

Information Technology (IT) outsourcing services include functions such as application development (web design development, e-commerce projects, etc.), network management, application maintenance (remote software maintenance, feature enhancements, etc.), and end user computing support such as internal record keeping, database, help-desk software etc. (Huff, 1991). Other outsourced functions include data entry and disaster recovery (Antonucci, Lordi, \& Tucker, 1998), operations, and facility management. IT outsourcing may either be either be a one-off, limited-duration or a long-term relationship. Several studies on IT outsourcing risks reveal the precarious nature of the outsourcing business (DiRomualdo \& Gurbaxani, 1996; Gallivan \& Oh, 1991; Keil, Cule, Lyytinen, \& Schmidt, 1998; Lacity \& Hirschheim, 1993; McCue 2005; Petrie, 2000a, 2000b; Project Management Institute, 2005; Power, Bonifazi \& De Souza 2004; Tafti 2005). Some of the risks associated with software development outsourcing are summarized in Table 1. Antonucci et al. (1998), Dibbern et al. (2004), Huff (1991), McFarlan and Nolan (1995), Mullin (1996), Power et al. (2004) and Turban et al. (2002) are among others who have described project risks in IT outsourcing more generally. Although financial risks, technological risks, and business risks are typically identified in literature (Elitzur \& Wensley, 1997; Tafti, 2005), risks of information loss or misuse due to technological obsolescence, knowledge diffusion, loss of personnel, moral hazard with hidden knowledge, loss of intellectual property, etc., is an area gaining great concern. Much of these risks accrue due to inadequate communication and documentation during the outsourcing project life-cycle. Managing the communication flow is therefore an important aspect of project management.

\section{Table 1: Potential Risks of IT outsourcing}

- High costs, occasional inefficiencies, potential source of morale problems, hidden expenses

- Shirking - a vendor deliberately underperforms while claiming full payment

- Poaching - a vendor using strategies and applications developed for one client for another client

- Re-pricing - the vendor changes the financial terms at some point in a long-term contract or overcharges for enhancements or extensions

- Technology evolution - because IT evolves rapidly, signing long-term contracts is risky

- Cost of switching to another vendor is often high

- Loss of control - outsourced vendor may not be as responsive to service levels as in-house employees, inability to control the vendor's costs, schedule, and technical quality

- Loss of morale due to layoffs or transfer of existing staff

- Less flexibility due to the need to use the vendor's computing platforms

- Could be locked in to vendors' proprietary software and hardware

- Misalignment between the company and the outsource vendor

- Micromanagement by the vendor with all the associated costs and implications

- Loss of control over critical strategic resources

Risk sharing is, hence, a common practice for parties adopting multiple outsourcing relationships. Gallivan and Oh (1999) provide insights into how the variations in the nature of the outsourcing relationships may shape the benefits and risks achieved from the deal and their influence on how uniquely the outsourcing relationships require to be managed. For example, on one hand cosourcing (the practice of providing similar services to multiple clients) has its advantages in risk sharing and reduction, as well as the accompanying constraints of knowledge diffusion risks; on 
the other hand, a simple one vendor - one client relationship is easy to coordinate and control but bears the constraint of being locked in with high switching costs for both parties. In as multivendor, single-client scenario, the benefit of allowing vendor specialization (and hence profitability) is offset by coordination costs and contractual complexities. In an outsourcing project, such dynamics need to be carefully managed with multi-point communications.

Managing cultural dimensions of global IT outsourcing relationships have also gained significance in recent outsourcing studies (Krishna, Sahay, \& Walsham, 2004). Gurung and Prater (2006) observed that cultural factors play an important role in the success of an outsourcing venture in addition to other factors such as relationship quality, outsourcing experience, and geographic distance. It is often argued that outsourcing companies should seek outsourcing vendors with similar values and cultures, as it would facilitate the establishment of 'common interest' and 'mutual understanding' to make the relationship a success. But this may often not be the case in practice, where availability of labor and cost cutting take precedence over choices based on cultural connection. More recently, Oza, Hall, Rainer, \& Grey (2005) in their study on outsourcing involving countries of different cultures state that client and vendors should have a balanced approach towards maintaining a relationship to be aware of the risks. Trust, therefore, emanates when both the parties have positive outlook on each others actions.

Thus, it can be noted that the success and longevity of an outsourcing arrangement is largely seen to depend on the client-vendor relationship (Webb \& Laborde, 2005), and recent research on outsourcing has shifted focus to how outsourcing relationships can be made to work. Following this trend, the research reported in this paper, rather than delving deeper into outsourcing theories and outsourcing risks or studying the array of outsourcing relationships, diverts towards the management of outsourcing relationships for successful IT outsourcing.

The study reported in this paper addresses the significance of technical communication in IT outsourcing, using perhaps the most knowledge intensive of such services - software application development and maintenance - as the domain of interest. More specifically, the study investigates how communication of valuable technical information between client and vendor can be made effective, leading to a successful IT outsourcing experience. This is obviously a long-term relationship rather than a one-off project as the typical life-span of critical enterprise software is often over 5 years (cf. Buchowicz, 1991; Dibbern et al, 2004; Pisano, 1990; Roberts \& Berry, 1985). The effectiveness of communication in this aspect is determined through the ability of the communication process to reduce risks in information flow and enhance trust building. Since human relationship is the basis for communication, the focal point is narrowed down to how communication choices can be made during outsourcing so that knowledge creation, sharing, and re-use are optimal. In so doing, it is hoped that lessons learnt as well as best practices from the field may be codified in the form of a framework for communications between vendors and clients.

\section{A Review of Background Work}

The field of professional communications draws from a vast body of knowledge - theoretic as well as experimental - that is of particular relevance to the research reported in this paper. It is therefore essential to review the basis of effective project communications including notions of risk and trust that must be managed, models for computer mediated communications, and how they may be applied to the context of project management. The following sub-sections provide such a review of the reported research in these topics. 


\section{Challenges to Outsourcing Success}

There are opinions that do not support the feasibility of IT outsourcing. Bettis, Bradley, and Hamel (1992) regard outsourcing (particularly of core competencies or key functions) as the surrender of a business capability to compete. Outsourcing may also diminish the control of the brand owner and makes it more difficult to implement design changes. The Gartner Outsourcing Summit 2005 in Los Angeles, California entitled "Practical Outsourcing: Managing the Choices, Risks and Rewards" revealed that hidden costs, high staff turnover, poor cross-cultural communications, and poor communication between the onsite and offshore project teams as well as between management and employees are the key reasons for poor management in outsourcing. The reason many outsourcing deals fail is because of the propagation of misinformation and confusion due to inadequate communications among the project team and its contacts, as well as within the general employees, executive ranks, and local community (McCue, 2005). Hence, eliminating risks and avoiding the pitfalls of outsourcing is a very valuable research area for industry practitioners. In this regard, notions of 'trust building' and 'effective communication' have gained attention in the IT outsourcing literature.

Effective outsourcing requires that clients and vendors have adequate level of shared knowledge concerning the components and services being provided (Yalaho, Nahar, Käkölä., \& Wu, 2002). Sung and Young (2003), who investigated the success and failures of outsourcing projects, suggested that a strong formation of relational exchange attributes between vendor and client is essential to successful project implementation. Their framework for helping IT managers in the ongoing management of outsourcing relationships emphasized the formation of relational exchange characteristics, communication behavior, and task characteristics as opposed to discrete exchange. Several research studies in inter organizational relationships have shown that a higher level of relational exchange characteristics has a positive effect on both polity performance (trust and satisfaction) and economic performance in inter-organizational arrangements (cf. Adler, 2003; Clemons \& Hitt, 1997; Dibbern et al., 2004; Gallivan \& Oh, 1999; Hines, 2005; Huff, 1991; Lee, 1996; McFarlan \& Nolan, 1995; Mulklin, 1996; Petrie, 2000a, 2000b; Ring \& van de Ven, 1992; Tafti, 2005).

International outsourcing of software development is a particularly risky and complex undertaking that attracts much technical communication effort and resources. The literature on outsourcing risks strongly emphasizes communication between the client and vendor as a critical requirement for a successful outcome - mostly meeting expectations of time, cost, and quality. It is much more a matter of getting the right knowledge to the right person at the right time. Or more specifically, making technical knowledge available in a form that can be used by practitioners who are working under pressure and in adverse conditions (Wenneker, Rijt, Selm, Nelissen, \& Wester. 2005).

Communicating complex technical information involves recognizing and responding to multilevels of knowledge (D'Arcy, 1998) and translating complex concepts in a way that adds to a person's knowledge. Although the term 'technical communication' generally refers to the propagation of technical information, it can be associated with technical documentation and technical communicators to technical writers. Generally speaking, technical communication encompasses communication activities that take place between a client and vendor based on the outsourcing contract managed by client as well as vendor project managers using different communication modes - from the exchange of information (explicit) to the sharing of nuanced intelligence (tacit).

Ives (2005) defines project management as "the application of knowledge, skills, tools and techniques to project activities to meet project requirements" ( $p$ 37). The extent to which these requirements are met within the constraints of time, cost and performance (or quality) defines success. In project success, trust had long emerged as an important ingredient (cf. Gallivan \& Oh, 
1999; Lee, 1996; McFarlan \& Nolan, 1995; J. K. Pinto \& Slevin, 1988; M. B. Pinto, Pinto, \& Prescott, 1993). Globally distributed software production is shaped and challenged by temporal, geographic, social, cultural, historical, technical, and political reasons (Orlikowski, 2002; Krishna, Sahay \& Walsham, 2004). Unless all these boundaries are traversed simultaneously, an international outsourcing project is likely to fail. Moreover, success of an outsourcing venture can be viewed with different parameters, such as the satisfaction gained from the outsourcing relationship, the fit between customer requirements and the outsourcing outcomes, or related to economic benefits and technological benefits (Gurung \& Prater, 2006). Trust in the client-vendor relationship is found to be a critical success factor for outsourced software development projects (Jennex \& Adelakun, 2003). If the client and vendor trust each other, contract administration in outsourcing relationships becomes easier (Adler, 2003; Power, Bonifazi \& De Souza, 2004; Tafti 2005; Webb \& Laborde, 2005). The absence of "trust building" in technical communication makes establishing trust much harder even within co-located teams (Richardson, Casey, Zage, \& Zage, 2005). Colleyer (2000) corroborates the telling link between the lack of adequate communications and the project team's failure to establish trust. Hence, it is meaningful to more fully understand the role of communications in creating conditions of trust and in turn managing risk.

\section{Perspectives on Computer-Mediated Communications}

Computer Mediated Communication (CMC) tools may be classified based on representation modes and interaction modes. Representation modes indicate the way communication tools may be used to present information, such as images, text, audio, and other media. Interaction modes indicate how people interact with others depending on the characteristic of the communication tools - conventionally, synchronous or asynchronous, symmetric or asymmetric. The basic communication model presumes that senders and receivers cooperate to create the communication (or information) and in so doing accomplish various outcomes (Haslett, 1987). Bos, Gergle, Olson, and Olson (2001) and Rocco (1998), among numerous others, have pointed out that face to face communication, no matter how brief, is the gold standard for knowledge and information exchange. But such communication has its restrictions of time, cost, and the synchronous availability of parties in geographically distant projects such as outsourcing (Carliner \& College, 1999). Hence project managers commonly make use of CMC tools such as email and web conferencing in order to reduce the need for costly face to face meetings.

Within the field of organizational communication, Media Richness Theory, first investigated by Daft, Lengel, and Trevino (cf. Daft \& Lengel, 1986; Daft, Lengel, \& Trevino, 1987) and reinforced by several others, serves as the most prominent (and perhaps controversial) theory of media choice. In essence, the theory describes organizational communication channels as comprising characteristics that determine each channel's capacity to carry rich information which is more capable than lean information of reducing equivocality or ambiguity in the receiving party. All communication channels (for instance, telephone, fax, conventional mail, e-mail, webconferencing, or broadcasting) possess attributes that lead to different richness capacities. Media richness hence refers to a channel's relative ability to convey messages that communicate nuances or contexts other than what is explicit. Less rich media may eventually do the same, but with more effort and time. Or alternatively, rich media communications ordinarily leads to information unambiguity and hence reduces risk.

As El Shinnaway (1998, p. 140), in a short commentary, explains: Communications that can overcome different frames of reference and clarify ambiguous issues to promote understanding in a timely manner are considered richer. Communications that take a longer time to convey understanding are less rich. The greater the mediums ability to express these factors [feedback capability, cues, personalization, language variety], the richer it is. Conventionally, the theory proposes that rich media such as face-to-face communication are ideal for situations requiring in- 
formation exchange and for creating shared meaning. Written media, in contrast are more suited for situations of low equivocality.

Despite widespread conviction among researchers and practitioners, mixed results have emerged for the interaction hypothesis suggesting that rich media is more effective for dealing with equivocal communication situations. Carlson and Zmud (1999), after an extensive survey of over a thousand academic colleagues, suggest that it is more than media richness; "if the sender perceives an e-mail message [for example] as being rich in information, but the receiver lacks the knowledge bases to interpret it richly, rich communication will surely not follow" (p 168). This is the notion of absorptive capacity that is part of the vocabulary of the knowledge management community (cf. Gupta \& Govinderajan, 2000). El Shinnaway (1998) cites the instance of "email, in spite of (or, more accurately, because of) its text based nature was deemed appropriate for most communication situations, both equivocal and non-equivocal" (p 140) because of other overriding considerations.

Building on media richness theory, and as an explanation to the mixed results from experiments, Zmud, Lind, and Young (1990) and later Carlson and Zmud (1999) have investigated a "channel expansion theory" which posits that experience with the use of a channel leads to greater perceptions of media richness and ultimately fulfils the objective of communication - contributing to a knowledge building experience. By "experience", they include not only usage experience with a channel but also the topic to be discussed, organization context, and familiarity with other communicating parties. In fact, greater usage experience alone is merely a "necessary but insufficient condition" for perceptions of media richness and, ultimately, effective communications. The notion of familiarity with the subjects (topic as well as people) leads to a "building of knowledge bases" which in turn allows "encoding and decoding of rich messages" over a given channel.

As a further layer of complexity, it has been suggested that most of the limitations of computermediated communication are due to the lack of interactivity associated with certain modes. Compared with face-to-face, computer mediated communication and telephone provide less feedback to the sender, and fewer sensory cues. For example, one of the greatest information risks with computer mediated communication is the 'question of authorship' - the identity of who wrote what is often blurred by the reposting of electronic messages (St. Amant, 2002). In this respect, face-to-face is considered to be more "media rich" than audiovisual media, which is more "media-rich" than audio-only or visual-only communication media (Greenspan, Goldberg, Weimer, \& Basso, 2000). Following this classification, computer mediated communications are the least "media rich". E-mail and computer conferencing create problems because communicators are unable to modify messages as they create them in response to signals from their communication partners (Carliner \& College, 1999). Rocco (1998, cited in Bos et al., 2001) found that groups meeting over email could not develop enough trust to reach the optimal outcome in a social dilemma, whereas groups meeting face-to-face did so easily and quickly. However, it was observed that interaction via e-mail was more trustworthy after a face-to-face brief. Galegher and Kraut (1990) also share similar views with respect to the limitations of computer-mediated communication such as:

- Direct responses to mass mails resulting in pair-wise interactions that undermine the level of mutual knowledge within the group as a whole.

- Uncertainties about the activities of others that do not arise when more direct contact is possible.

- During project planning and the integration of interim products, it is often helpful for all members of a workgroup to be able to view, refer to, and manipulate a shared document or other artifact, which email does not provide. 
Sophisticated users of CMC are understandably very selective in their choice of channels and presentation (Walther, 1997). They mask the cues that senders find unattractive by taking advantage of the shortcomings of the medium and give attention to providing informative cues and pointers in a deliberate manner. Such users are highly susceptible to the nuances of communicating with partners as a basis of interpersonal communication. When they begin their interaction, the expected future communication supposedly will lead to increased social information exchange (Walther, 1997).

Wenneker et al. (2005) view information and communication technologies as complementary to face-to-face contact which they concede (like many others) is the most important communication channel for sharing knowledge. Meanwhile, Kraut, Galegher, and Egido (1988) conclude that computer mediated communication will be more valuable for coordinating already existing collaborative projects than for starting new ones, suggesting that kick-off meetings and teambuilding activities be distinctly handled.

Face-to-face communication is more than synchronous information exchange; utterances and gestures are largely unplanned, although the topic and basic themes may have been (Greenspan et al, 2000). Bos et al. (2001) demonstrate that trust can emerge in synchronous mediated conditions, albeit slowly, when they tested trust in four different communication situations: face-to face, video, audio, and text chat. In asynchronous communication, the context is not jointly created during the communication, so more than one context can be defined: the context of creation (the sender's) and the context of use (the receiver's) (Haslett, 1987). For example, in e-mail and voice mail, the content is created long before the recipient receives it. Whereas face-to-face meetings tend to include more frequent, less formal exchanges. In contrast, email exchanges tend to be more serious but less frequent and produce a greater sense of control among participants (Bonk, 1998). Thus, an understanding of the context is necessary for effective communication in asynchronous modes, as doing otherwise can produce noise or miscommunication.

\section{Trust Building in Technical Communication}

Research consistently indicates that a good outsourcing contract is the foundation for a successful outsourcing relationship (Clemons \& Hitt, 1997; Lacity \& Hirschheim, 1993; Lee, 1996) and that many potentially beneficial outsourcing opportunities are probably lost because contracts cannot be negotiated (Clemons \& Hitt, 1997) effectively. It has also been observed that trust arising from a close outsourcing relationship may lessen the perceived likelihood of demands for renegotiation of contract (Elitzur \& Wensley, 1997).

Though there are several contractual measures in use today to ensure successful outsourcing experience, relationships between vendors and their clients are based on more than what is explicit in the contract (cf. Adler, 2003). A closer look at outsourcing contracts shows that many of them do not include specifics of technical communication processes between the client and vendor. Even meticulously crafted and planned contracts do not cover all situations (Webb \& Laborde, 2005). Thus, contracts are unable to entirely address certain risks involved, such as the ones due to information misuse and loss, due to their very intangible nature. It is also essential for the contract to be perceived by both parties as fair and mutually beneficial to exude trust in the engagement (Webb \& Laborde, 2005). This is a critical starting point for effective technical communications - that a commonality of interest is established.

Following from the above discussion, a contract addresses the 'holy trinity of outsourcing' elements of price, scope, and time. Hence, it requires establishing calibrated communication channels to enable the prompt delivery of contractual obligations. A communication breakdown at any point between the parties would pose a huge threat to the timely flow of information. Power distance (Hofstede, 2001), differences in language, and the people culture of communicating knowl- 
edge (Carliner \& College, 1999) are also seen to determine the extent of information shared and frequency of communication. Cross-cultural communication complicates the task of translating complex social and material contexts into simple and understandable procedural instructions for specific audiences (Krishna et al. 2004). This may create information 'no sharers' who would be guilty of 'cultural bigotry' such as not wanting to communicate openly with someone from a certain culture. Thus, the main concerns are low trust levels due to cultural differences and risks due to the politics of miscommunication when people involved are not able to communicate face to face, frequently, and casually across borders and time zones. In such situations, alternative facilities and systems need to be devised to meet communication needs varying over time and tasks (Gurung \& Prater, 2006).

The development of software, an exemplar of IT outsourcing, is carried out over multiple periods in multiple stages such as design, multiple stages of coding, integration, testing, implementation, parallel operation, and full operation (Constantinescu, 2005; Culnan, 1985; Richardson, Casey, Zage, \& Zage, 2005). Similar to any intellectual team work that demands extensive information sharing and coordination, software outsourcing projects typically involve an initial phase during which group members settle on an interpretation of the problem, define their goals and plan their work, an execution phase during which team members may work independently to carry out the various tasks associated with the project, and an integration phase during which team members bring their individual inputs together to create a final product (Bikson \& Eveland, 1990; Finholt, Sproull, \& Kiesler, 1990; Kraut, Galegher, \& Egido, 1988; McGrath, 1990). During this time period, frequent or periodic communication is scheduled with activities such as routine project meetings, scope changes, user support, delivery of milestone reports, arbitration of issues such as non performance penalties, audit of service levels, top management review, stakeholder training, addressing culture gaps, and other project coordination activities (Ives, 2005). Thus, it is a critical function of a project manager to ensure that effective communication takes place right through such disparate phases through the use of platforms and tactics. The background to this is examined next.

\section{Communications Platforms and Tactics}

Communication modes have three functionalities: communication, information storage and retrieval, and collaboration (Wenneker et al., 2005). The mode of communication adopted is particularly germane as it is "the communication medium that makes lying possible" (Killingsworth, 1999, p. 6) and at the same time, develop trust. Choosing a communication platform is a balance between trust and risk. The use of technology for communication "may breed distrust and is always liable to loss or mechanical failure" (Killingsworth, 1999, p. 5), adding to the risks. A strong stream of communication research has shown that different communication modalities may be useful at successive stages in the life of a long-term project (Kraut, 1990) such as outsourcing. Some of the modes include direct, synchronous communication via personal meetings, teleconferencing, video conferencing; computer mediated communication via email, instant messaging, e-newsletters that serve as periodic updates to the project team, web repositories in which client and vendor team members upload and share files or download documents for sharing or critique, instant messengers and internet conferencing which include application sharing in addition to the conventional audio, video and text. Zmud et al (1990) suggest that managers modify their communication media and mode based on the needs of task and issues associated with the receiver. The criteria for selection includes both physical access and the ability of the mode to meet the quality expectations for the communication, such as confidentiality and reliability (Culnan, 1985; Zmud et al., 1990), and providing the number, variety, and richness of possible cues (Daft et al, 1987; Sproull \& Kiesler, 1986). 
Table 2: Computer-mediated communication modes

\begin{tabular}{|l|l|l|l|l|}
\hline & $\begin{array}{l}+ \text { Synchrony } \\
+ \text { Symmetry }\end{array}$ & $\begin{array}{l}\text { + Synchrony } \\
- \text { Symmetry }\end{array}$ & $\begin{array}{l}\text {-Synchrony } \\
- \text { Symmetry }\end{array}$ & $\begin{array}{l}\text {-Synchrony } \\
+ \text { Symmetry }\end{array}$ \\
\hline $\begin{array}{l}\text { Audio } \\
\text { Only }\end{array}$ & Telephone & Streaming Audio & $\begin{array}{l}\text { Interactive Voice } \\
\text { Response }\end{array}$ & Voice Mail \\
\hline $\begin{array}{l}\text { Visual } \\
\text { Only }\end{array}$ & $\begin{array}{l}\text { Instant Messaging: } \\
\text { Electronic Whiteboards }\end{array}$ & $\begin{array}{l}\text { Web-based GUI; } \\
\text { Webcam }\end{array}$ & Web Pages & Email and Fax \\
\hline $\begin{array}{l}\text { Audio- } \\
\text { Visual }\end{array}$ & $\begin{array}{l}\text { 2-way Video: } \\
\text { Collaborative Workspaces }\end{array}$ & $\begin{array}{l}\text { Webinars and } \\
\text { Webcasts }\end{array}$ & $\begin{array}{l}\text { Web Interactive } \\
\text { TV }\end{array}$ & $\begin{array}{l}\text { E-mail with } \\
\text { attachments }\end{array}$ \\
\hline $\begin{array}{l}\text { Text } \\
\text { Only }\end{array}$ & Online chat & $\begin{array}{l}\text { Real-time } \\
\text { discussion forum }\end{array}$ & $\begin{array}{l}\text { Electronic } \\
\text { Newsletters }\end{array}$ & Text messaging \\
\hline
\end{tabular}

For example, Table 2 shows how communications modes may be distinguished along various dimensions that are important to communications such as audio-visual availability, synchrony, and channel symmetry. Synchronous refers to the real-time nature of an interactive communications session while symmetry defines the existence of a directional channel with equivalent bandwidth (and hence media richness). Although Media Richness Theory would suggest that the more sophisticated the platform, the more effective the communication, the art of selecting an effective communication platform is also influenced by cost, geographical distance, cultural, and time differences.

It is particularly important to make informed communication choices when dealing with international, culturally diverse audiences. The rapid evolution of information and communications technology enable computer mediated communication to provide a direct and faster means of intercultural communication, changing the way in which people think about space and time, but may amplify cultural rhetorical differences (St. Amant, 2002). Setlock, Fussel, and Neuwirth (2004) have found significant differences in synchronous computer-mediated communication among different cultures. St. Amant (2002) also highlights Edward Hall's context model on the importance of knowing the context in inter cultural communications. As computer mediation does not provide cues about people identities or the social network they belong to, it lacks context information that people from certain cultures need to determine how to interact in a given situation. This may leave participants uncomfortable, frustrated, or reserved as they are unable to gauge what is acceptable or unacceptable behavior. Sometimes, the new degree of proximity could lead to new levels of expectations that may lead to cross cultural misunderstandings. Such occurrences tend to result in lost time and money or may hurt cross-cultural relationships and trust levels. Also, if computer mediated communications are not taken as seriously or genuinely as face-toface, such activities may result in poor productivity. A prompt anticipation of potential areas of conflict or miscommunication that may arise due to the "faceless, anonymous" dimension of computer mediation (St. Amant, 2002) would help in the development of effective communication strategies for an international online environment. Krishna et al. (2004) similarly address the complexities of international, inter-cultural communication and suggest that the use of "coordination and control mechanisms" such as computer mediated communications, in order to be effective, must be tempered by expert relationship management, training, and staffing. Harmonization for the purpose of project control is best achieved through the use of common methodologies, processes and platforms. 
Hence, it is clear from the literature that the design of an effective communications platform for IT outsourcing require careful selection of modes, media and channel. In the next section, a model that synthesizes the key findings from the background literature will be described.

\section{A Conceptual Framework for Effective Technical Communication}

The fundamental premise of the research is that 'technical communication' is an attribute that can be developed independent of the variables affecting outsourcing relationships. These variables (such as outsourcing project success, mutual understanding, trust, and information risks) are perceived to be dependent on the effectiveness of the technical communication process. There are also intra-dependencies observed between these dependent variables themselves. Thus, several associations cited in the literature could have been formulated based on the following three fundamental postulates:

\begin{tabular}{|c|c|}
\hline Postulate 1 & $\begin{array}{l}\text { Effective technical communication during project management of an IT out- } \\
\text { sourcing contract enhances trust }\end{array}$ \\
\hline Postulate 2 & $\begin{array}{l}\text { Effective technical communication during project management of an IT out- } \\
\text { sourcing contract reduces information risks }\end{array}$ \\
\hline Postulate 3 & $\begin{array}{l}\text { Effective technical communication during project management of an IT out- } \\
\text { sourcing contract hence results in project success }\end{array}$ \\
\hline
\end{tabular}

In other words, adopting best practices for technical communications leads to a relationship of increased trust and creates conditions for reduced information risks, which in turn are codependent on each other. The final desired outcome is undoubtedly project success, as defined by time and budget constraints being met in order to fulfill client requirements.

\section{Deriving the Model and Research Questions}

Whereas the critical need for effective technical communication in project management has been long recognized, it is evident from the literature that little research has been undertaken in the area of IT outsourcing. By and large, project managers on both sides function by the rule of tradition - do what has been done in the past. A holistic, systematic, and specific good practices framework is therefore necessary to guide effective technical communication in the various phases of a complex international IT outsourcing project. Hence, the idea of a best practices framework is central to this research question: how can effective technical communication support project success in IT outsourcing? 


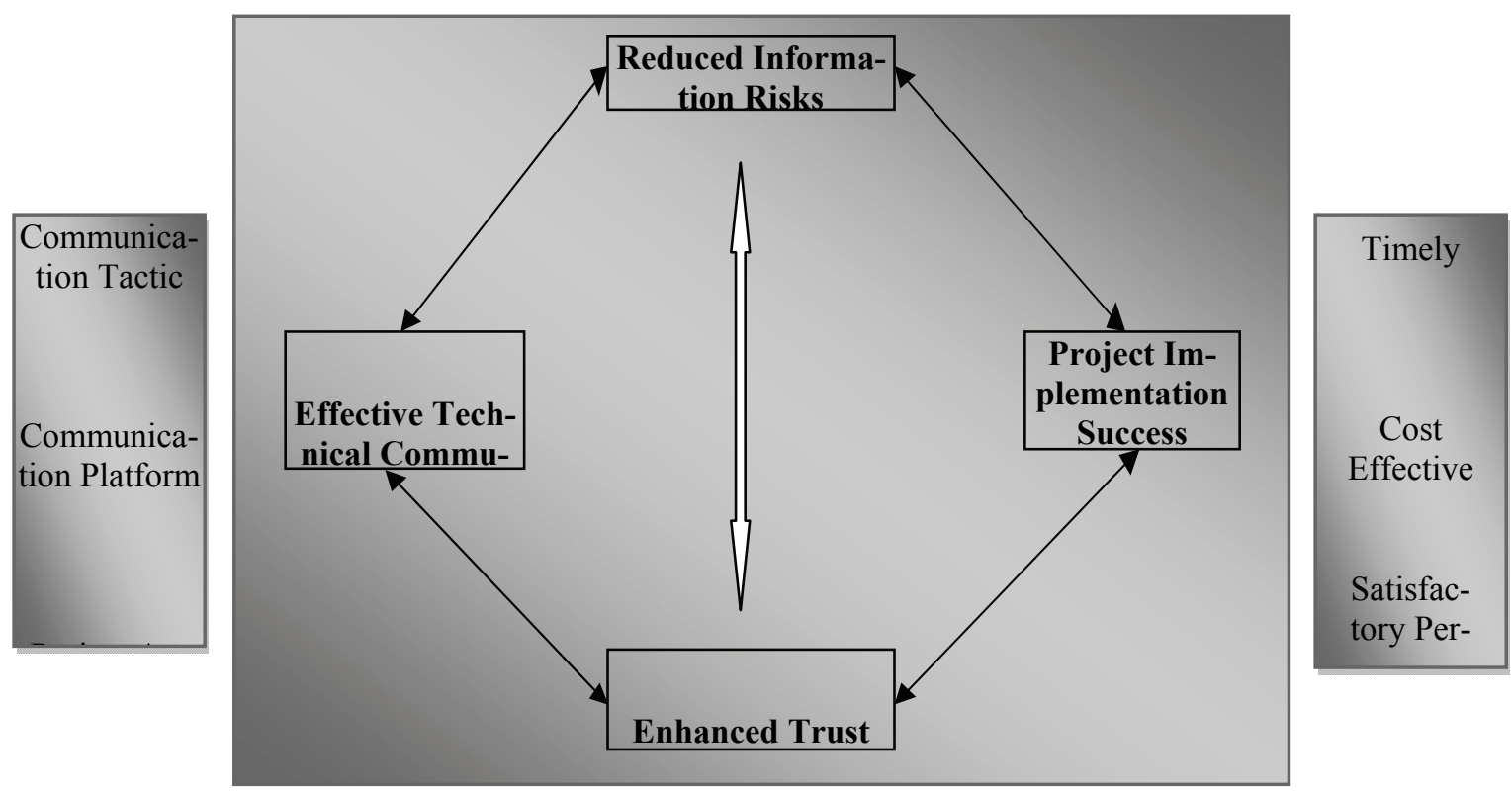

Figure 1: A Conceptual Research Model for Effective Technical Communication

Recall that project success has traditionally been assessed in the context of cost, time, and quality (J. K. Pinto \& Slevin, 1988; M. B. Pinto, Pinto, \& Prescott. 1993; PMI 2005), where an environment of trust is the major driver and risk the major inhibitor of the desired outcome. As in Bos et al. (2002) and Jensen et al. (2000), this study also evaluates the positive effects of collaborative use of communication modes on these success factors but differs in that it views communication modes in the context of outsourcing projects only. The central hypothesis of the research is that these success factors are a consequence of effective technical communication. The conceptual model was developed to provide a reflective idea of what constitutes effective communication and its major factor of influence - the communication platform comprising modes, media, and channels. The model thus establishes a tactic for effective technical communication to manage these relationships. Figure 1 illustrates a synthesis of views supported in the literature. Contingent associations between technical communications, trust, risk, and project success and the choices for information and knowledge exchange spanning the various communication modes, media, and channels must fit a communication tactic and project activity. The framework conceptualized in Figure 1 is by no means comprehensive nor complete. We shall revisit its completeness in the concluding section. At this phase of the research, we had intended to develop a model based on our belief system (defined by the 3 central postulates in Table 3 ) and allowed further investigation of some interesting research hypothesis (to be described in Table 5).

Based on the literature reviewed in the area of IT Outsourcing and using the framework of Yalaho $\& \mathrm{Wu}(2002)$, various communication modes and outsourcing project communication activities could be identified. Yalaho and Wu's model discusses how communication modes are used to support outsourcing activities in software development. More specifically, the framework identified (1) the different phases in outsourcing, (2) the major communication activities in each phase, (3) the expected outcomes, performance measures and the IT tools used at each phase, and (4) which IT tool support the phases in general and each phase in particular. The themes from the model enabled the grouping of the several IT outsourcing communication activities identified from the different phases drawn by Yalaho and $\mathrm{Wu}$ in order to identify potential risks. These are 
summarized in Table 4 and are used later in the research for the purpose of constructing the field survey instrument.

Table 4: Effective Technical Communication in Outsourcing

\begin{tabular}{|c|c|c|c|c|c|c|}
\hline \multirow[b]{2}{*}{$\begin{array}{l}\text { Outsourcing } \\
\text { Communication } \\
\text { Activity }\end{array}$} & \multirow[b]{2}{*}{$\begin{array}{l}\text { Possible informa- } \\
\text { tion risks / reduc- } \\
\text { tion in trust }\end{array}$} & \multicolumn{3}{|c|}{$\begin{array}{c}\text { Mitigating Communication Tactic and } \\
\text { Outcome }\end{array}$} & \multicolumn{2}{|c|}{$\begin{array}{c}\text { Mitigating Communication } \\
\text { Platform }\end{array}$} \\
\hline & & $\begin{array}{l}\text { Inform to } \\
\text { understand }\end{array}$ & $\begin{array}{l}\text { Negotiate } \\
\text { to accep- } \\
\text { tance }\end{array}$ & $\begin{array}{l}\text { Regulate to } \\
\text { fulfillment }\end{array}$ & $\begin{array}{l}\text { Mode of com- } \\
\text { munication } \\
\text { (synchronous, } \\
\text { symmetric) }\end{array}$ & $\begin{array}{l}\text { Media } \\
\text { Richness } \\
\text { and Chan- } \\
\text { nel Capacity }\end{array}$ \\
\hline $\begin{array}{l}\text { Routine project } \\
\text { meetings }\end{array}$ & $\begin{array}{l}\text { Information hoard- } \\
\text { ing }\end{array}$ & $\sqrt{ }$ & & & V & $\sqrt{ }$ \\
\hline Scope changes & $\begin{array}{l}\text { Change from leg- } \\
\text { acy system to new } \\
\text { system causing } \\
\text { information }\end{array}$ & $\sqrt{ }$ & $\sqrt{ }$ & $\sqrt{ }$ & & $\sqrt{ }$ \\
\hline User support & $\begin{array}{l}\text { Loss of Intellectual } \\
\text { Property }\end{array}$ & $\sqrt{ }$ & & & $\sqrt{ }$ & \\
\hline $\begin{array}{l}\text { Delivery of mile- } \\
\text { stone reports }\end{array}$ & $\begin{array}{l}\text { Information Gap } \\
\text { due to time zone } \\
\text { difference and } \\
\text { organization poli- } \\
\text { cies }\end{array}$ & $\sqrt{ }$ & & & & \\
\hline $\begin{array}{l}\text { Arbitration of } \\
\text { issues such as non } \\
\text { performance pen- } \\
\text { alties }\end{array}$ & $\begin{array}{l}\text { Delivery delay, } \\
\text { temporary absence } \\
\text { of service }\end{array}$ & & $\sqrt{ }$ & $\sqrt{ }$ & $\sqrt{ }$ & $\sqrt{ }$ \\
\hline $\begin{array}{l}\text { Audit of service } \\
\text { levels }\end{array}$ & $\begin{array}{l}\text { Disagreements } \\
\text { due to gap in legal } \\
\text { contract }\end{array}$ & & $\sqrt{ }$ & $\sqrt{ }$ & & $\sqrt{ }$ \\
\hline $\begin{array}{l}\text { Informing vendor/ } \\
\text { client organiza- } \\
\text { tion of changes } \\
\text { that effect them }\end{array}$ & $\begin{array}{l}\text { Staff are leaving } \\
\text { mid project leading } \\
\text { to loss of tacit } \\
\text { knowledge/ gap in } \\
\text { team role }\end{array}$ & $\sqrt{ }$ & & & $\sqrt{ }$ & \\
\hline $\begin{array}{l}\text { Addressing cul- } \\
\text { tural gaps }\end{array}$ & $\begin{array}{l}\text { Culturally distant } \\
\text { vendors }\end{array}$ & $\sqrt{ }$ & & & $\sqrt{ }$ & $\sqrt{ }$ \\
\hline $\begin{array}{l}\text { Training (address- } \\
\text { ing KID gap) }\end{array}$ & $\begin{array}{l}\text { Diffidence due to } \\
\text { organizational } \\
\text { silos politics }\end{array}$ & $\sqrt{ }$ & & & $\sqrt{ }$ & $\sqrt{ }$ \\
\hline $\begin{array}{l}\text { Stemming knowl- } \\
\text { edge attrition }\end{array}$ & $\begin{array}{l}\text { High staff turnover } \\
\text { leading to loss of } \\
\text { corporate memory }\end{array}$ & $\sqrt{ }$ & & & $\sqrt{ }$ & \\
\hline $\begin{array}{l}\text { Top management } \\
\text { review }\end{array}$ & $\begin{array}{l}\text { New management } \\
\text { does not support } \\
\text { outsourcing }\end{array}$ & $\sqrt{ }$ & $\sqrt{ }$ & & $\sqrt{ }$ & \\
\hline
\end{tabular}

There are a myriad of interactive effects among the constructs of the proposed model that may be derived. For example, it has been suggested that when frequency of communication is important, asynchronous communication modes would be more effective. Synchronous communication is effective when familiarity between the parties is most essential. A symmetric channel is necessary when source and recipient roles alternate in the information or knowledge sharing that takes place during project activities. When both regularity and familiarity are essential, initial face-to-face or 
direct communication followed by regular computer mediated communication is preferred. Many best practice companies suggest the importance of establishing vital one-to-one relationships with their clients at the earliest stage possible and subsequently reduce media richness and channel capacity. Many of these conventional practices have not been tested in the field of IT outsourcing project activities.

The research model articulates the major dimensions of effective technical communications and the contingencies or interactions among them. Based on the model, research assertions were derived (in a manner to be described in the next section on research methodology) in order to test its applicability to project communication practices in the field. There are two groups of assertions stated in Table 5. The first set of assertions developed associate the project communication activities with the communication platform (mode, media, and channel). Communication requires cooperation between two contracted parties in an outsourcing project - the client and the vendor. With the use of certain modes, it is no longer necessary that the communicators are in direct contact with one another (cf. A1 - A4 in Table 5). The choice of communication modes required during outsourcing activities differ with distance. Hence, assertions were also drawn to make comparisons between the various asynchronous and synchronous communication modes best suited for outsourcing activities (cf. A5 - A13 in Table 5). These assertions have to do with the use of specific communications channels for the purpose of resolving typical project issues.

\section{Table 5: Research Questions to be Field Tested}

A1. Information risks are often controlled by building trust through the use of appropriate communication tactics, modes, media and channels.

A2. Regular face-to-face communication increases trust between client and vendor and therefore reduces information risks during communications, and is hence, necessary for project success.

A3. There is a need to meet members of my vendor/client team in order to trust them and effectively communicate with them.

A4. Inability to communicate regularly and casually with the vendor/client can reduce trust.

A5. Email is more effective than direct communication as they avoid gaps due to culture differences and are hence more helpful for successful project outcome.

A6. Email is better than telephone for responding in an effective manner to increase trust and is hence important for project success.

A7. When there is a time zone difference with the client/vendor, asynchronous modes such as email and fax are preferable to telephone or audio-video conferencing.

A8. Task responses to telephone communication are quicker than to email communication and hence reduce uncertainty and risks.

A9. Video conferences are preferred to telephone conferences as they induce more trust and reduce risks of misunderstanding information.

A10. The use of discussion forums and web repositories are more effective than project discussions by email.

A11. The use of newsletters and bulletins directed to the project team (as part of the communication plan) creates awareness, reduces information gaps and hence controls disruptive behavior such as information hoarding, seeking individual glory and even knowledge attrition.

A12. Discussion forums are more effective than net meeting for communicating complex project issues.

A13. Discussing critical project issues through audio or video conferencing is more effective than email or discussion forums. 
The conceptual model developed provided a framework for spawning field testable research assertions and, hence, identifying best practices measures for effective technical communication. The methodology for deriving and field testing the assertions will be described in the following section.

\section{Field Research Methodology}

Despite the longstanding debates about media richness and channel selection theories in the field of communication, the practice of project communication is still in its infancy. There is no available framework of best practices for the project manager to draw from. In an effort to investigate this, the field research was conducted at two phases. The first was to conduct an exploratory study spanning several organizations in order to obtain a broader "first cut" view of how organizations manage IT outsourcing. This empirical investigation was conducted, and initial exploratory data was gathered through qualitative interviews with Chief Information Officers of government agencies. Hence, using the equivalence of the Critical Success Factors and Delphi approaches favored by field researchers (cf. Palvia, Sharma, \& Conrath, 2001 for an overview of field research issues), feedback on some fundamental research questions distilled from a body of knowledge was systematically derived from a panel of experts until some distinct consensus on what constituted outsourcing project success emerged.

The derived research assertions that were spawned from the conceptual model were next checked for face and construct validity in the same process of interviewing some 20 senior IT managers with considerable experience in project management on either side of the IT outsourcing business - client and vendor. The structured interviews with such practitioners enabled confirmatory results about trust and information risks in IT outsourcing activities for subsequent statistical sampling against widely held common beliefs in technical communication practices. The results, both quantitative and qualitative in nature, identified relationships, trends, and disconnects between the factors influencing project success.

\section{Research Design}

An online survey instrument was designed for collecting the required responses from practitioners. Once the communication mode and the various outsourcing activities were identified and listed, it was then possible to address questions based on the assertions made. The survey instrument was calibrated for cohesiveness, user friendliness, and scalability with three rounds of pilot testing with fellow researchers and then industry practitioners. Changes were incorporated based on an analysis of the response pattern and participant inputs. Following from the assertions, the survey instrument hence consisted of sections with the following themes:

- Communication Mode and Information Risks

- Communication Mode and Trust

- Communication Mode and IT Outsourcing Project Success

- Communication Mode Preferences and Practices in IT Outsourcing Activities.

The final-form of the tool consisted of 5 sections with both quantitative and qualitative questions. The questions on the first two sections of the survey were designed to first elicit practitioner responses on what constitutes project success and then establish associations between effective technical communications and desired outcomes. These were mostly obtained using a 5-point Likert scale, as shown in the screen shot in Figure 2. In the survey, "choice of communication mode" could be equated with "effectiveness of the communication mode", and can be interchangeably referred as "choice of the most effective way to communicate" or "effective technical communication". 


\begin{tabular}{|c|c|c|c|c|c|c|}
\hline A A Survey of Technical Communication Practices in Outsourcing - Microsoft Internet Exp & & & & & & $x$ \\
\hline Eile Edit $\quad$ View $F$ Favorites Iools Help & & & & & & At \\
\hline 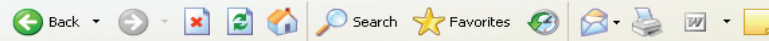 & 约 8 & & & & & \\
\hline 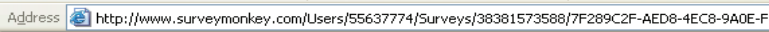 & $9 \mathrm{C} 93 \mathrm{~F} 843 \mathrm{E}$ & asp?U=38381573 & \&DO_NOT. & YY_THIS_LINK & $\rightarrow$ Go & Links ” \\
\hline A Survey of Technical Communication Practices in Outsourcing & & & & & this survey & $\gg$ \\
\hline 2. Please choose your views on communication modes for enhancing & ust anc & educing risk & aiding $\mathrm{t}$ & tter project & outcome: & \\
\hline & $\begin{array}{l}\text { Mostly } \\
\text { Agree }\end{array}$ & $\begin{array}{l}\text { Somewhat } \\
\text { Agree }\end{array}$ & Neutral & $\begin{array}{l}\text { Somewhat } \\
\text { Disagree }\end{array}$ & $\begin{array}{l}\text { Mostly } \\
\text { Disagree }\end{array}$ & \\
\hline $\begin{array}{l}\text { Information risks are often controlled by building trust through the use of } \\
\text { appropriate communication modes such as face to face, email, web, } \\
\text { telephone, video conferencing etc. }\end{array}$ & 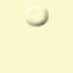 & 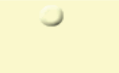 & $\smile$ & $\smile$ & 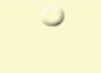 & \\
\hline $\begin{array}{l}\text { Regular face to face communication increases trust between parties and } \\
\text { hence is most essential for project success. }\end{array}$ & J & J & J & 0 & 0 & \\
\hline $\begin{array}{l}\text { I do not need to meet a person from my vendor/client team in order to trust } \\
\text { them and effectively communicate with them. }\end{array}$ & J & 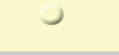 & 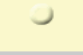 & 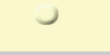 & $\smile$ & \\
\hline $\begin{array}{l}\text { Inability to communicate regularly and casually with the vendor/ client can } \\
\text { reduce trust. }\end{array}$ & 0 & 0 & 0 & 0 & 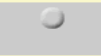 & \\
\hline $\begin{array}{l}\text { Email is more effective than direct communication as they avoid gaps due to } \\
\text { culture differences and are hence more helpful for successful project } \\
\text { outcome. }\end{array}$ & J & $\mathcal{U}$ & 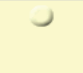 & Ј & Ј & \\
\hline $\begin{array}{l}\text { Email is better than telephone for responding in an effective manner to } \\
\text { increase trust and is hence important for project success. }\end{array}$ & 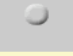 & 0 & 0 & $J$ & J & \\
\hline $\begin{array}{l}\text { When there is a time zone difference with the vendor, email and fax is } \\
\text { preferable to telephone, audio or video conferencing. }\end{array}$ & 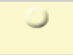 & Ј & $\mathcal{~}$ & 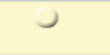 & J & \\
\hline $\begin{array}{l}\text { Task responses to telephone communication are quicker than emails and } \\
\text { hence reduce risks. }\end{array}$ & 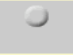 & 0 & 0 & $J$ & 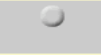 & \\
\hline $\begin{array}{l}\text { Video conferences are preferred to telephone conferences as they induce } \\
\text { more trust and reduce risks of misunderstanding information. }\end{array}$ & 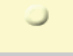 & J & $\mathcal{J}$ & 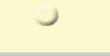 & Ј & \\
\hline $\begin{array}{l}\text { The use of discussion forums and web repositories are more effective than } \\
\text { overloading project discussions by emails. }\end{array}$ & 0 & 0 & 0 & 0 & 0 & \\
\hline Done & & & & - In & & \\
\hline
\end{tabular}

Figure 2: Screen Shot of Section 2 of the Survey Instrument

The third section of the survey consisted of multiple-choice selections of preferred modes of communications during the various project activities. A screen shot of this is shown in Figure 3. The survey instrument in its entirety can be found in the following URL http://www.surveymonkey.com/s.asp?u=38381573588.

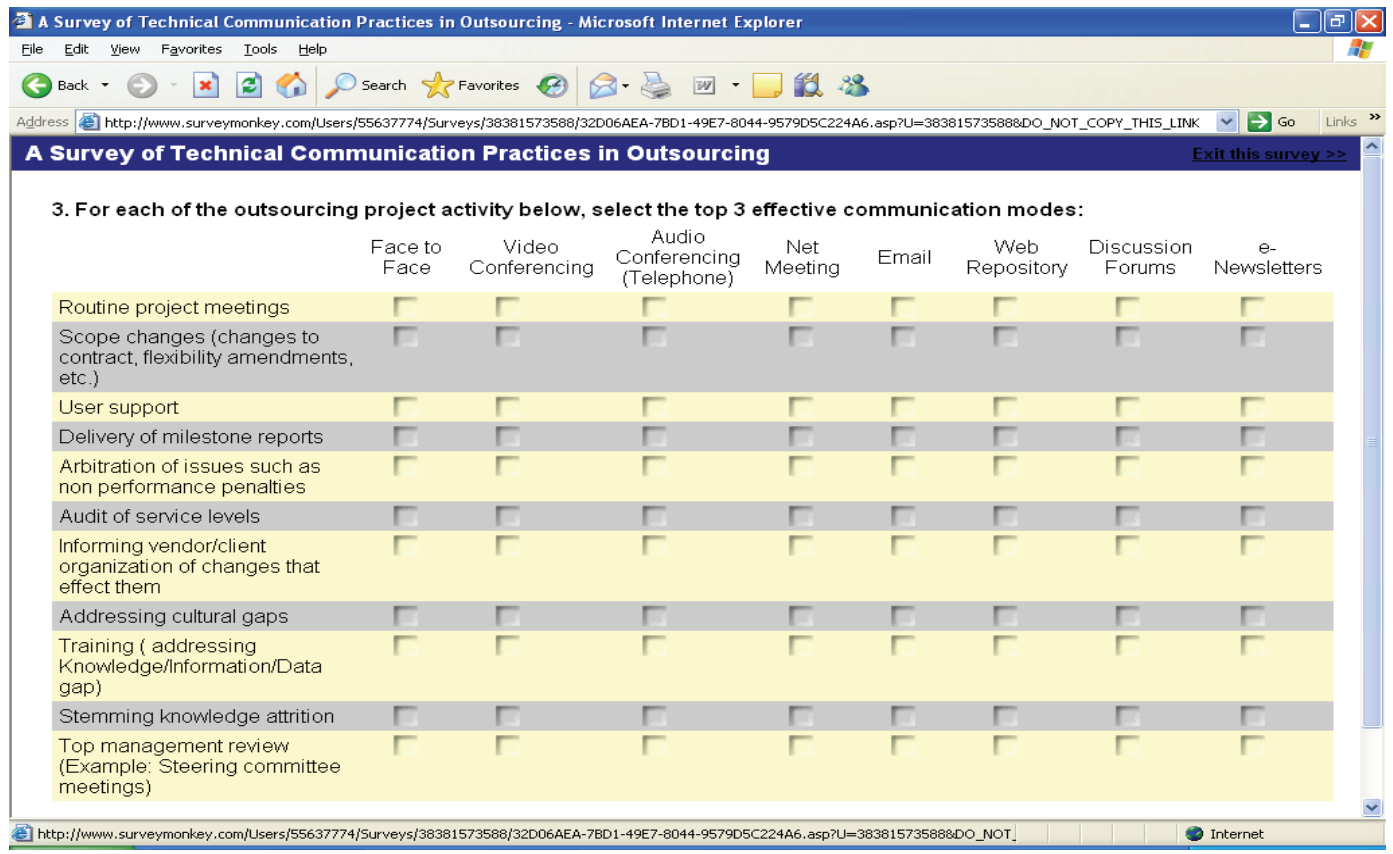

Figure 3: Screen Shot of Section 3 of the Survey Instrument 


\section{Field Data Collection}

The consensus obtained from the literature and the Delphi panel was that the research assertions were comprehensive and parsimonious in addressing the fundamental questions pertaining to best practice norms in project communication. The activities, modes, and outcomes used to design the survey do not claim to be minute, but form a "deep dive" attempt to identify the support for good practices per se. The intent of the field investigation was hence to unearth the issues confronting effective technical communication in the practice of outsourcing. The results would ideally be more than statistics; for instance a feel of the pulse of perspectives between clients and vendors.

The field survey was carefully conducted as follows. Middle to senior level project managers and CIOs who have been part of at least one full IT outsourcing life cycle in their organizations were approached for their considered judgments. While IT experience was by no means the criterion, respondents were specifically asked to disqualify themselves if they did not have the knowledge nor exposure to the issues that were asked of them. The respondents were also asked to participate in any follow up in-depth interview if needed. The data collection anticipated ethical or political difficulties in the research process. All the responses collected were kept anonymous and confidential. No personal demographics were collected to avoid any ethical or political discomforts that may arise. Hence, respondents were not required to identify themselves or their firms and no respondent profile was sought (nor reported). This anonymity constraint later led to a feeling of regret among the research team (and the reviewers of this research!) about what may have provided ample data to investigate any variances in the perspectives of clients across industries, project management practices across cultures, or even differences according to the types of outsourcing projects. At that time, we were discouraged from performing any further respondent profiling for the same reason of not wanting to breach our assurances of anonymity and hence risking a lower response rate. As an incentive for participation, the respondents were told that they would have access to the results and findings of the study conducted if they emailed the research team with such a request. It was interesting to note that over $80 \%$ of the respondents were indeed interested in the results.

The link to the online survey was distributed via email to CIOs, project managers and outsourcing managers of multi-national organizations, public sector agencies and IT software developers from offshore companies across India, Singapore, New Zealand, the United Kingdom and the United States - chosen because they are nodal locations for the client or vendor side of the IT outsourcing business. The survey was also distributed to professional associations and Special Interest Groups of project managers interested in technical communications and their participation was sought via direct and personal email after first having secured a buy-in from their management. Responses were received from 71 practitioners - 43\% vendors, $29 \%$ clients and the rest declining to respond to this particular question (presumably for fear of identification). Most of the respondents were involved with software development outsourcing - perhaps the most complex of IT outsourcing projects - though about a third of the respondents also dealt with follow-up functions such as software maintenance and support. Thus, the sample involved practitioners (across different industries, organizations and countries) who were immersed in some form of software development outsourcing activity and in a position to reflect on their experience.

\section{Results and Discussion}

As a "first cut" field investigation, much of the analyses of the results were amenable to descriptive, rather than inferential statistics. In the next sub-section, the level of support for the 13 research assertions is presented. Following this, the discussion covers some interesting observations about practitioners' preferences for various communications platforms in carrying out the myriad project activities. Finally, some qualitative comments from the field and their interpretation are presented. 
As a cursory test for face and construct validity, a quick response on the level of support for the fundamental postulates was elicited. The wording used in the survey question was posed in a form opposite to postulates in order to rule out the possibility of "agreeability" among respondents. The results (shown in Table 6) can be summarized in terms of simple descriptive statistics that give an indication of the relative support for the various practices in technical communications. Scores of $\{-30-1001030\}$ were given to responses \{mostly disagree; somewhat disagree; neutral; somewhat agree; mostly agree respectively and their means standard deviations and $\mathrm{z}$ values (for a two tailed test) computed conventionally. Although we do not claim any psychometric qualities to the assignment of these scores to the Likert ratings, they were specifically chosen to lend greater credence to respondents with strong, definite reactions than those who tended to be lukewarm or neutral in their assessments. Hence we did not choose a more simple linear transformation of the Likert scale to ordinal values of $\{0,2.5,5,7.5,10\}$. Leedy and Ormrod (2005) suggest that such a transformation of data that is ordinal and non-parametric (as is the case with any attitudinal survey) is more a choice of design rather than convention. In our data analysis, we wished to give greater weight to respondents who took a more definite position in their ratings.

\section{Table 6: Tabulation of Support for Fundamental Postulates}

\begin{tabular}{|c|c|c|c|c|c|c|c|}
\hline & Postulates & $N$ & $\begin{array}{l}\text { Mean } \\
(m)\end{array}$ & $\begin{array}{l}\text { Standard } \\
\text { Deviation } \\
\text { (SD) }\end{array}$ & $\begin{array}{l}Z=(m-\mu) \\
\sqrt{ } N / S D \\
(\text { where } \\
\mu=0)\end{array}$ & $\begin{array}{ll}95 \% & \text { Confi- } \\
\text { dence } & \text { Inter- } \\
\text { val of } & \text { SD }\end{array}$ & $\begin{array}{l}P \\
\text { Value }\end{array}$ \\
\hline P1 & $\begin{array}{l}\text { Communication mode does not } \\
\text { matter in order to trust a person } \\
\text { with good technical communica- } \\
\text { tion skills. }\end{array}$ & 70 & -5.8 & 33.8777 & -1.4324 & $\begin{array}{ll}29.0473 & \text { to } \\
40.6500\end{array}$ & 0.1520 \\
\hline P2 & $\begin{array}{l}\text { Communication mode does not } \\
\text { matter in order to reduce informa- } \\
\text { tion risks. }\end{array}$ & 68 & -15.8 & 40.7333 & -3.1986 & $\begin{array}{l}34.8522 \\
49.0206\end{array}$ & $0.0014 *$ \\
\hline P3 & $\begin{array}{l}\text { Communication mode does not } \\
\text { play a role in project success. }\end{array}$ & 70 & -22.6 & 58.9983 & -3.2049 & $\begin{array}{l}50.5862 \\
70.7923\end{array}$ & $0.0014 *$ \\
\hline
\end{tabular}

Not surprisingly, there is statistically significant $(\mathrm{p}<.025)$ support for the postulate that effective technical communication reduces information risks (P2). There is also significant support for the central postulate of this research that effective technical communication contributes to successful project outcome (P3). P1 was deliberately worded in an ambiguous manner (in contrast to the actual postulate stated in Table 3). Again this was to test for the possibility of a trend among respondents to consistently agree or disagree. The result was that in this case, the null hypothesis could not be rejected; in other words, there were neither considerable agreement nor disagreement among respondents. Good technical communication skills seem to override the availability or lack of CMC. Cronbach's Alpha (a measure conventionally used to express internal consistency) for attitudinal responses for the 3 postulates and 13 assertions was calculated to be in excess of $80 \%$. Hence it may be claimed that the field survey instrument exhibits acceptable validity and reliability. 


\section{Descriptive Analysis of Research Assertions (A1 - A13)}

Next, similar two-tailed $\mathrm{z}$ tests were done on each of the 13 research assertions. In this test, there was statistically significant support $(\mathrm{p}<.025)$ for all but Assertions $3,5,6,8$ and 9 . This indicates that the use of CMCs in IT outsourcing project management is a nuanced art which depends much on the other contextual factors. More revealing was the descriptive statistics summarizing practitioners' views. Some brief comments on each assertion follow.

A1: 95\% of respondents agree that information risks can be controlled by using appropriate communication modes. There is almost no disagreement on this assertion-extremely significant agreement. This is also a reliability verification of the result of P3 where $72 \%$ agreed to a similar view. This also shows that information risks can be reduced by engaging in trust building activities.

A2: $83 \%$ of respondents believe that regular face to face communication increases trust between parties, making it most essential for project success. Despite the very significant support for face to face communication, only half of the respondents completely agree. 44\% somewhat agree indicating that regular face to face is not the only basis for building trust or not the 'most essential' element for project success. Thus, face to face meetings can vary between 'essential' to 'nice to have'. Other factors of time, cost and availability would obviously take over the rationale of face to face meetings, which are also contributing factors towards project success.

A3: $50 \%$ of respondents agree and 43\% disagree that they need not meet their vendors/clients to be able to trust and communicate with them. $8 \%$ of respondents are neutral in their views. While an initial face-to-face meeting followed by subsequent mediated communication may be conducive for trust building and communication to many, an about equal portion consider this to be a luxury that is not practiced.

A4: $76 \%$ of respondents agree that the inability to communicate regularly and casually with the vendor/client can reduce trust. This is statistically significant. More than half the respondents agree that they need regular communication with their vendor/client. Casual and regular communication serves as a trust building exercise and helps in forging trust between the parties to outsourcing.

A5: $46 \%$ of respondents agree that email is more effective than direct communication (telephone or face to face) for reducing gaps due to cultural differences and hence, such communication is better for successful project outcome. Not statistically significant, the disparity of views to this assertion can be attributed to the prevailing widespread dependency on email communication. The views on email reducing intercultural communication gaps does gain considerable support from half the population but is also refuted by one third of the respondents $(30 \%)$. This finding seems congruent with channel expansion theory which posits that usage experience and perceptions determine the eventual effectiveness of a given channel.

A6: $36 \%$ of respondents agree and an equal number disagree that email can be better than telephone for effective communication. This assertion tests email communication versus the telephone as modes for building trust. Again not statistically significant, this may be attributed perhaps to their familiarity with e-mail communication. In practice, there is a tendency of following up email with telephone, which enables the building of trust. The choice of communication mode is more often based on the nature of information that needs to be communicated or the mode the sending party first adopts, that may subsequently be used as the preferred mode.

A7: $61 \%$ of respondents prefer to communicate via email or fax rather than audio, video or web-conferencing, when there is a time zone difference between the client and vendor. This assertion tests if asynchronous communication is more effective than synchronous communication when parties are separated by time zones. The preference of the respondents indicates the signifi- 
cant support for asynchronous communication in such situations.

A8: $53 \%$ of respondents prefer telephone communication to email communication for responses to tasks, although this is not statistically significant. This assertion compares email and telephone communication in their ability to reduce risks and information gaps. Respondents prefer telephone communication to email communication when they require a quick response. This avoids gaps and risks due to time delays or omissions, making telephone communication most effective in such situations.

A9: $51 \%$ of respondents agree that video conferencing is better than telephone conferencing in its ability to build trust and reduce. A third of the respondents could not choose between the two. There is a clear preference, though, for video communication in a person's ability to trust. It is more than a conjecture and consistent with Media Richness Theory that facial expressions, gestures and body language help in a clear communication of intent that creates little doubts in the minds of the communicators. This finding builds on the previous one that, if face to face three dimensional communication is not possible, a two dimensional video conferencing is the "next best thing".

A10: 68\% of respondents believe that discussion forums and web repositories are more effective than emails for activities related to project discussions. This assertion tests the preference amongst asynchronous but symmetric computer mediated communication modes and support for the finding is extremely significant. The response justifies the increasing use of web repositories and sophisticated internet tools for sharing knowledge. Email communication may also be frustrating and imposing for some, due to flooding or hoarding. These information risks are avoided in forums and repositories, as it can largely support the preferences of the communicator.

A11: 69\% of respondents support the view that organizational politics can be reduced by the practice of distributing uniform information through newsletters and bulletins. This assertion tests the need for transparency and open communication and there was very significant support among practitioners. Intuitively, every member of an outsourcing project team has the right to know'. Once this is satisfied, trust levels are improved and there is lesser risk of any member hiding information. Thus information risk due to organizational politics may be reduced as there is a degree of accountability and unity which the practice of distributing 'common' knowledge brings about.

A12: $51 \%$ of respondents neither agree nor disagree that discussion forums can be more effective than virtual meetings for communicating complex project information. While this assertion tests the effectiveness of computer mediated communication in complex discussions; more specifically, that of net meeting over discussion forums. Discussion forums were found to be more effective than emails in project discussions because of their ability to support collaboration and open communication. It is believed that complex issues are better solved with a greater degree of interactivity and synchrony, by the use of computer facilitated virtual meetings using tools from the collaborative products.

A13: 78\% of respondents agree that critical project issues are more effectively discussed through audio or video conferencing than email or discussion forums - a statistically significant number. This assertion is an extrapolation of the previous finding. Both confirm the need for a 'human touch' in the effectiveness of discussing critical or complex information. As critical project issues may directly influence the success of the project outcome, parties do not take the risk of emailing for fear of miscommunication. The ability to trust and the assurance that there are no risks, gaps or misunderstandings is most important during such communications. 


\section{Communications Preferences of Practitioners}

The respondents were also asked to indicate their three most preferred modes of communication and their least preferred mode of communication for each of the listed outsourcing activities. The results may be grouped as synchronous and asynchronous communication modes, a classification of prime importance in the outsourcing context. In this section, we make some observations from this part of the survey results.

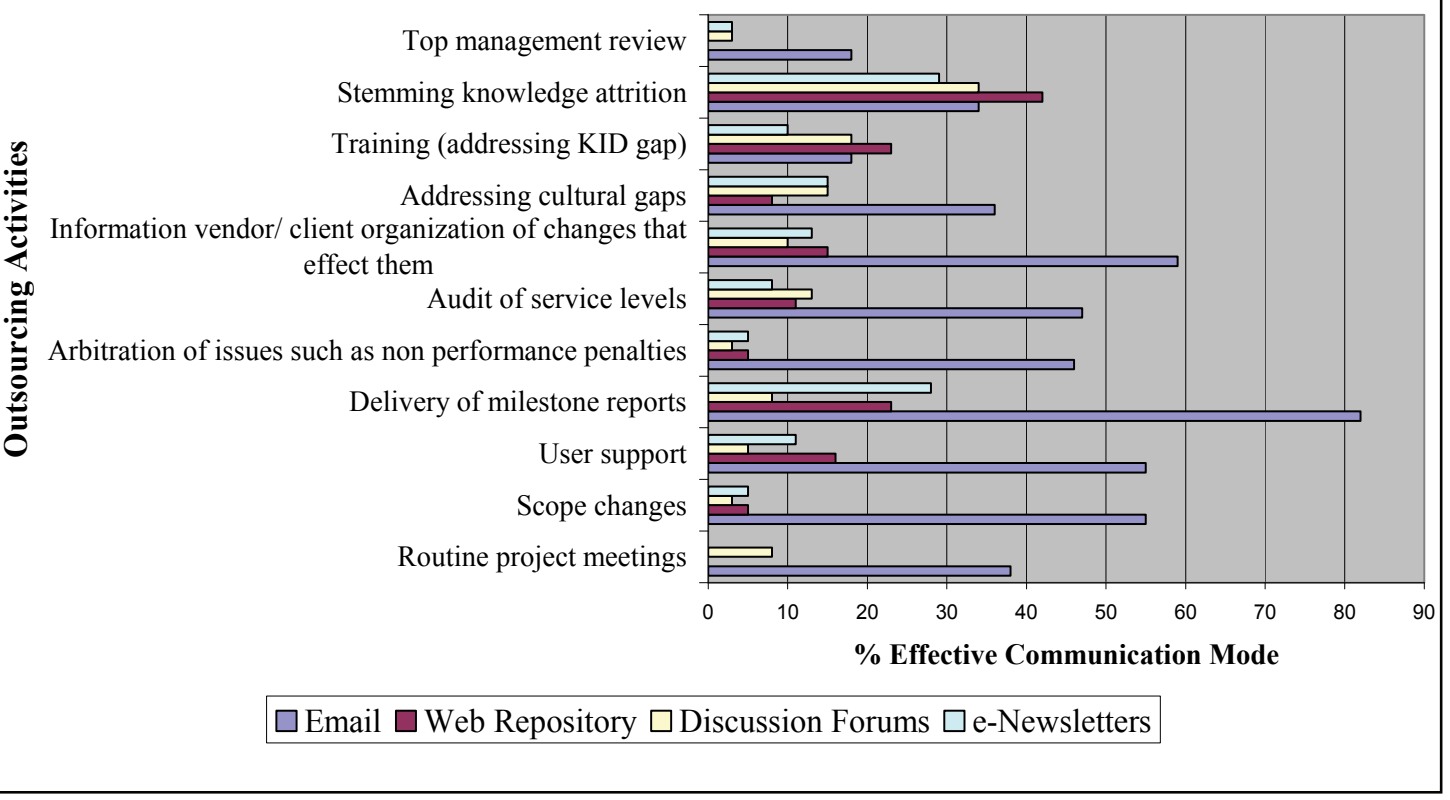

Figure 4: Effective Asynchronous Communication Modes for Project Activities

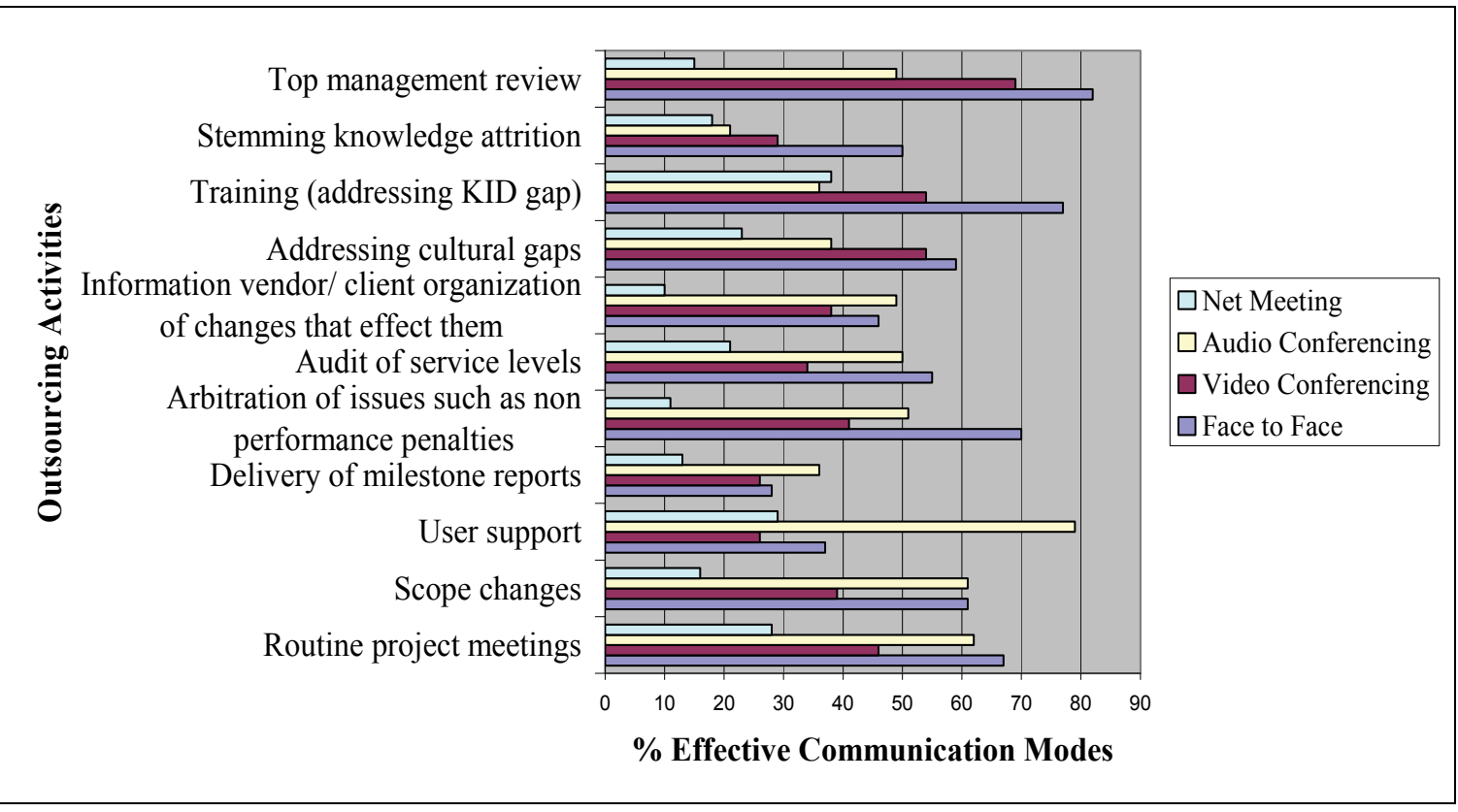

Figure 5: Effective Synchronous Communication Modes for Project Activities 
Figures 4 and 5, extracted from the responses to the section of the survey shown in Figure 3, address these choices. They show the percentage of responding practitioners who selected a particular communication mode as one of their top three choices for a given project activity. It may be discerned that there is a general preference for synchronous communication over asynchronous communication for most project activities. Except for the delivery of milestone reports and for informing vendors or clients of changes, communications support for most other activities are found to be more effective when synchronous. This suggests that coordination and control activities particularly require interaction and direct communication.

Also, email was reported by respondents to be the most effective asynchronous communication mode for all activities except stemming knowledge attrition which was reported to be more suited for web repositories. It corroborates Kinney and Watson's (cited in El Shinnaway, 1998) observation that the text email provides a most ubiquitous and versatile communications channel.

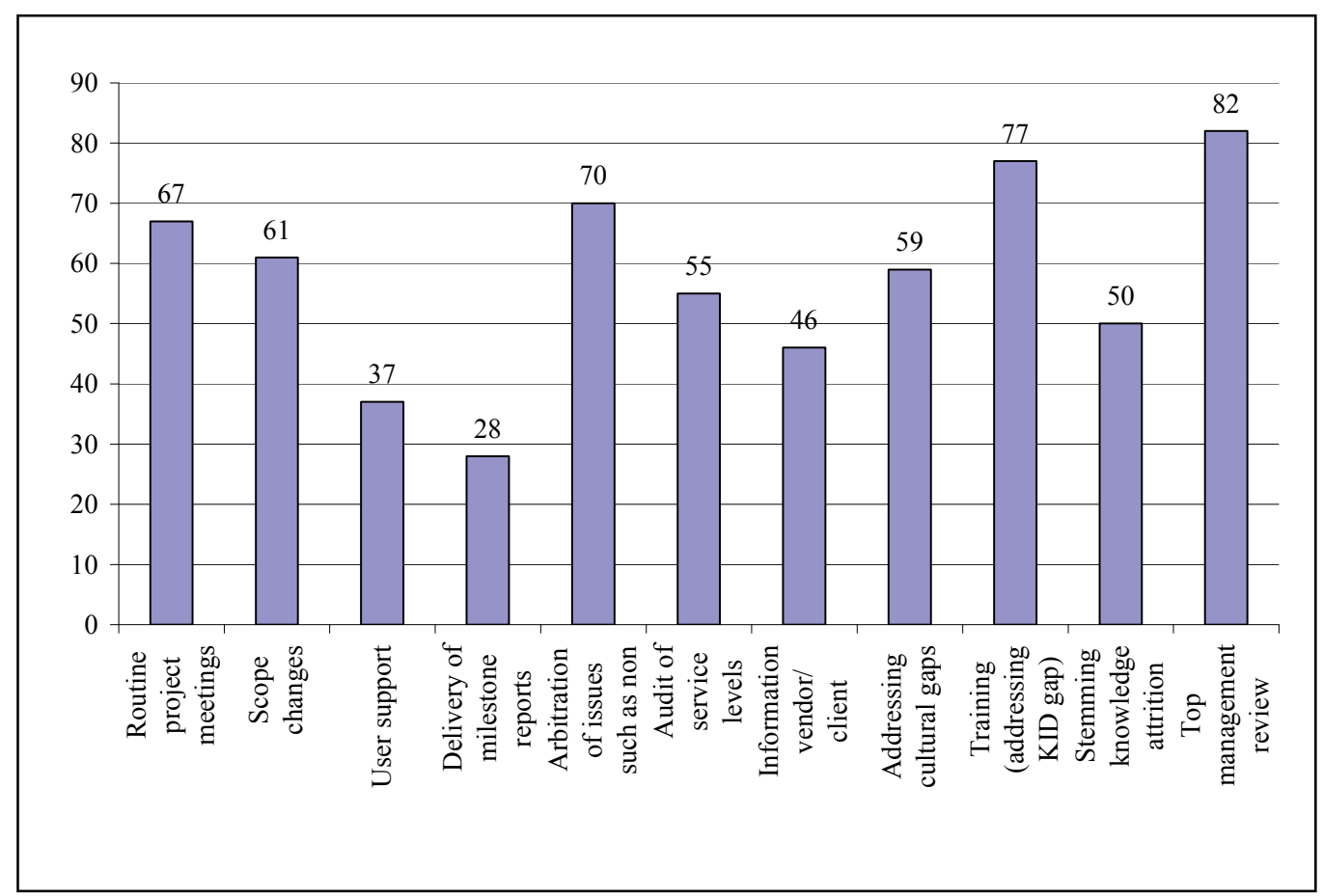

Figure 6: Preference for Face-to-Face Communications

However, it was clear that the gold standard for communication between vendors and clients during IT outsourcing remains face-to-face interactions. Figure 6 corroborates what has been evident from the CMC literature that "Face to Face" is the most effective mode of communication for most project activities. Such communication is preferred for 8 out of the 11 activities. This is unsurprising and reflects the age old adage that such contact is essential in a relationship which requires the establishment of trust. Audio conferencing (or using the telephone) is the most preferred for communicating scope changes, audio conferencing is most effective for providing user support, and email is the most effective mode of communication for the delivery of milestone reports and providing information about organization changes to the vendor or client. It is also noteworthy that Figure 6 confirms that top management reviews are most effectively conducted face to face. This is perhaps the most value-laden of project activities. There seems to be a unanimous choice of synchronous communication for top management reviews. 


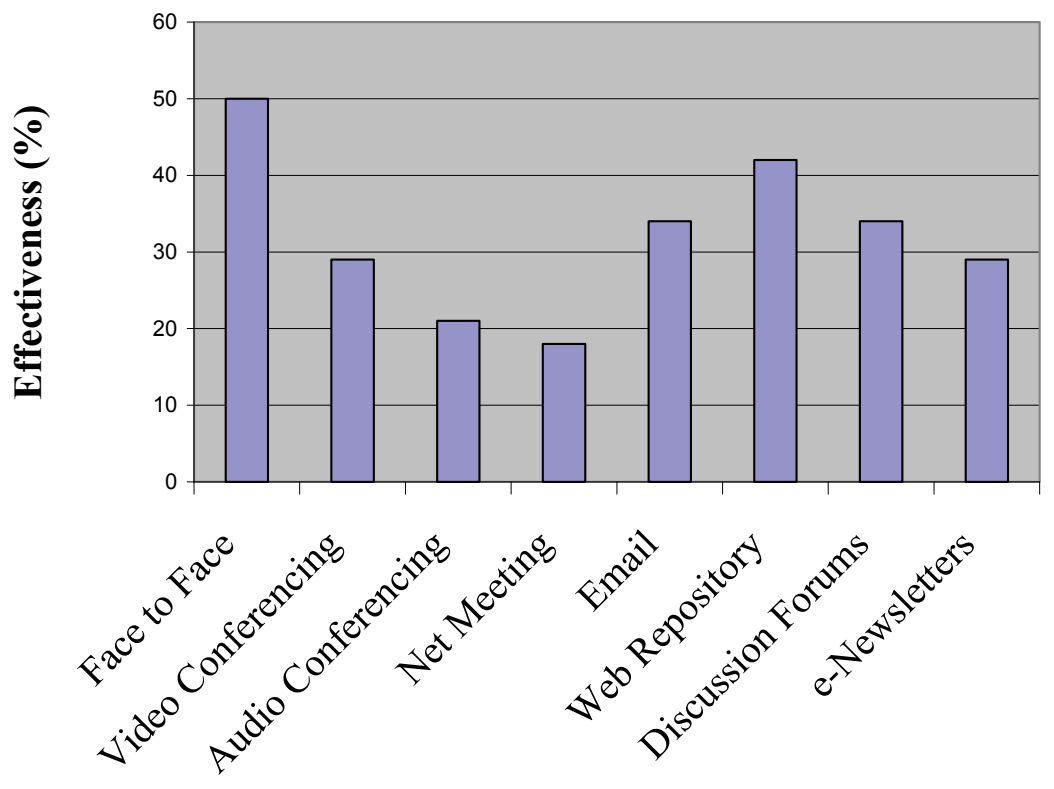

Figure 7: Stemming Knowledge Attrition

Figure 7 indicates that there is, overall, an even spread of representation for all communication modes in stemming knowledge attrition. This suggests that knowledge attrition can be effectively addressed through most of the communication modes. This may also mean that the issue is most effectively communicated with the use of multiple communication modes.

We can similarly conclude that asynchronous communication modes seem better for stemming knowledge attrition and delivery of milestone reports. Within the scope of the survey, e-mail was considered by practitioners to be the most effective asynchronous communication mode for such project activities, particularly in the transfer of codifiable, explicit knowledge. This question on the survey served as a test of whether practitioners would go overboard with the choice of the richest media and highest channel available for each and every project activity; apparently not.

To revisit the notion of an appropriate fit between project activities and communication modes, it is instructive to examine how effective (or ineffective) each of the communication modes is for a particular outsourcing activity. This may help in the tactic of deciding which mode to select when the first preference is not available. Table 7 provides a ranked order of the three most effective and least effective communication modes that were declared for each of the outsourcing activities. Recall that for a suite of typical project activities, respondents were asked to indicate the three most effective communications modes (cf. Figure 3) and, later, the least effective.

At a glance, it is once again clear that face-to-face communication is indeed the most ubiquitous. Audio and sometimes video (for nuanced contexts) conferencing are well-considered alternatives, especially when distance is a factor and symmetric, synchronous communication is desired. It is interesting to note that change management (a critical project activity) is one of the few which is well served by either synchronous and symmetric or asynchronous and asymmetric communication modes. 


\begin{tabular}{|c|c|c|c|c|}
\hline \multirow[t]{2}{*}{ Outsourcing Activity } & \multicolumn{3}{|c|}{ Most Effective Communication Modes } & \multirow{2}{*}{$\begin{array}{l}\text { Least Effective } \\
\text { Communication } \\
\text { Modes }\end{array}$} \\
\hline & 1 & 2 & 3 & \\
\hline Routine Project Meetings & Face to Face & $\begin{array}{l}\text { Audio } \\
\text { Confer- } \\
\text { encing }\end{array}$ & $\begin{array}{l}\text { Video Con- } \\
\text { ferencing }\end{array}$ & $\begin{array}{l}\text { Web Repositories/ E- } \\
\text { Newsletters }\end{array}$ \\
\hline Scope Changes & $\begin{array}{l}\text { Face to Face/ } \\
\text { Audio Con- } \\
\text { ferencing }\end{array}$ & Email & $\begin{array}{l}\text { Video Con- } \\
\text { ferencing }\end{array}$ & Discussion Forums \\
\hline User Support & $\begin{array}{l}\text { Audio Con- } \\
\text { ferencing }\end{array}$ & Email & Face to Face & Discussion Forums \\
\hline Delivery of Milestone Reports & Email & $\begin{array}{l}\text { Audio } \\
\text { Confer- } \\
\text { encing }\end{array}$ & $\begin{array}{l}\text { e-Newsletter/ } \\
\text { Face to Face }\end{array}$ & Discussion Forums \\
\hline $\begin{array}{l}\text { Arbitration of issues such as } \\
\text { non performance penalties }\end{array}$ & Face to Face & $\begin{array}{l}\text { Audio } \\
\text { Confer- } \\
\text { encing }\end{array}$ & Email & Discussion Forums \\
\hline Audit of Service Levels & Face to Face & $\begin{array}{l}\text { Audio } \\
\text { Confer- } \\
\text { encing }\end{array}$ & Email & E-Newsletters \\
\hline $\begin{array}{l}\text { Informing Vendor/Client } \\
\text { organization of changes that } \\
\text { effect them }\end{array}$ & Email & $\begin{array}{l}\text { Audio } \\
\text { Confer- } \\
\text { encing }\end{array}$ & Face to Face & $\begin{array}{l}\text { Net Meeting/ Discus- } \\
\text { sion Forums }\end{array}$ \\
\hline Addressing Cultural Gaps & Face to Face & $\begin{array}{l}\text { Video } \\
\text { Confer- } \\
\text { encing }\end{array}$ & $\begin{array}{l}\text { Audio Con- } \\
\text { ferencing }\end{array}$ & Web Repository \\
\hline $\begin{array}{l}\text { Stakeholder Training } \\
\text { (Addressing Knowledge / } \\
\text { Information/Data Gap) }\end{array}$ & Face to Face & $\begin{array}{l}\text { Video } \\
\text { Confer- } \\
\text { encing }\end{array}$ & Net Meeting & E-Newsletter \\
\hline $\begin{array}{l}\text { Stemming Knowledge } \\
\text { Attrition }\end{array}$ & Face to Face & $\begin{array}{l}\text { Web Re- } \\
\text { pository }\end{array}$ & $\begin{array}{l}\text { Email/ Dis- } \\
\text { cussion Fo- } \\
\text { rums }\end{array}$ & Net Meeting \\
\hline Top Management Review & Face to Face & $\begin{array}{l}\text { Video } \\
\text { Confer- } \\
\text { encing }\end{array}$ & $\begin{array}{l}\text { Audio Con- } \\
\text { ferencing }\end{array}$ & Web Repository \\
\hline
\end{tabular}

\section{Qualitative Responses on Effective Project Communications}

In the concluding section of the field survey, three open ended questions were posed to responding practitioners in order to glean industry attitudes on some best practices as well as pitfalls of project communications. 
Practitioners responded that common information risks such as sending an email to a client with an incorrect response to a query was a typical situation which warranted tools which could have avoided the mistake. This was akin to asking for the equivalence of a context "spell-checker".

Others responded that, regardless of media or channel, technical communication is effective without the use of jargon and buzz words during the user requirement gathering stage. It was critical that end-users and business analysts possessed adequate technical communication skills as it involved the vendor to communicate with technology novices from business units. The vendor had to break down technical details in a manner easy to understand for the support staff and business unit heads and at the same time effectively communicate the information gathered to the project team with all the technical details intact. Hence the use of a project dictionary or glossary was called for.

Negotiation of tender documents was found to be most effective when conducted through face-toface meetings. Offsite software implementation testing, project timeline discussions, and support seemed to require robust technical communication. A support agreement required technical communication between the client and vendor to explain support concepts such as service level agreements, $24 * 7$ availability of support, and to discuss other specific requirements. Another situation was during software product testing where a technical walkthrough of the functionality of the application using an appropriate mode such as net meeting helped the testing team to better understand the functions. It was suggested that the communication platform gave the team a better understanding of the product thereby increasing effectiveness.

A noteworthy perception among respondents was the need for technical communicators to be more business savvy than technology centric. As a respondent (presumably a client from Finance) commented, "I'll be better off talking about interest rates swaps than the oracle database". This induces the need to develop parallel tracks during a communication session. As Channel Expansion Theory suggests, it is more than the channel and has to do with the domain knowledge as well. A strictly technical discussion does not necessarily improve trust levels in the communication, especially during long distance communications.

Hence, communication practices grounded on a principle of sound management philosophy and economic reality help to develop client relationships. Computer mediated communications enable outsourcing practitioners to respond and adapt to business changes and provide a mechanism for the alignment of objectives. A continuous improvement framework for communication could keep an organization at the forefront of innovation through dynamic and effective client relationship management with a shared communications platform.

Different levels of technical capabilities due to a lack of knowledge or experience or to staff rotation sometimes cause misinterpretations, inhibitions, and poor understanding. Research by Carlson \& Zmud (1999) and Krishna et al. (2004) allude to this inequity in knowledge levels being a key attributing factor to ineffective communication. Moreover, technical constraints and gaps in design specifications are unavoidable project deterrents. A regular communication and validation approach would overcome this barrier. Lack of domain knowledge, operational knowledge, or hands on experience is a critical barrier for outsourcing practitioners that can hamper their ability to communicate effectively. Technical information can be lost during translation when there are too many intermediaries present in the communication process. Hence, it is by no means orthogonal that training and staffing are also key elements of the subsequent effectiveness project communications, as Krishna et al. (2004) suggest.

However, consistent with what has been reported in the research literature (cf. Adler, 2003; D’Arcy, 1998; Greenspan et al., 2000; Finholt et al., 1990; Krishna et al., 2004; M. B. Pinto et al., 1993; Sproull \& Kiesler, 1986; Walther 1997; Zmud et al. 1990), respondents suggested that the barriers to effective technical communication could be more social than technical. Differences in 
language, culture, and personalities affect a person's ability to trust. Inability to trust leads to an inability to effectively communicate. But even when two parties trust each other, communications may fail due to several other reasons. One suggested reason was the lack of 'empathy'. In other words, a technical communicator needs the soft-skills to be intuitive about his audience's needs while preparing the content of delivery.

Trust, effective communication, and client relationship management were repeatedly noted as the critical success factors for an outsourcing project to be managed for desired results. Most of the attributes for project success could be related to the ability of the technical communicator to effectively convey project data, information, and knowledge (DIK) to the team. Regardless of the communications platform, a skilled technical communicator is greatly responsible for the sharing of project DIK. Some of the commonly suggested attributes were: the ability to clearly communicate, provide clear documentation, schedule regular follow ups with pre-set deliverables, use trusted communication modes, provide regular information updates, possess the ability to match requirements with good support structure and capabilities, possess the ability to build trust, the ability effectively manage teamwork, and general contract management. The role of a communications platform, though secondary, and skillfully applied communications tactics are evident.

\section{Concluding Remarks}

The discussions and findings reported in this paper have illustrated the nature of technical communication in IT outsourcing and its nuances. During the study, the need for developing a best practice framework for effective technical communication emerged. There is as yet no framework for the practitioner of IT outsourcing that links the choices made in project communication to the reduction of risks and enhancement of trust.

It can be gathered that most of the risks in an outsourcing project arise due to the "notorious" time-cost-quality trade-off problem. The practitioner has a dire need to understand the best practices of the art and use it to enhance project coordination and control. The findings of the field research have resulted in distilling a framework that attempts to address this issue. Hence, to recap the central ideas of technical communications related to the project management of IT outsourcing that have been captured through a review of the literature and field survey:

- An effective information and communication strategy is a central component of successful outsourcing.

- Technical communication plays a key role in making an outsourcing project a success.

- Communication relationships in outsourcing are largely moderated by the communication tactics and platform adopted.

- Effective technical communication reduces information risks.

- Effective technical communication induces trust.

- An environment of reduced information risk and increased trust leads to project success.

It is hoped that the major contribution of this research is that it adds to the body of knowledge available to the project manager of a complex IT outsourcing contract. Success is critical to both client and vendor and they have the great responsibility of 'making it work'. Technical communication in an environment of reduced risk and enhanced trust leads to a greater chance of achieving the intended delivery outcomes. The mode, media, or channel adopted may induce their audience to trust and avoid risks for a certain activity, but this should not be a source of concern for the communicator. Adherence to a communication strategy and adopting the best practices for 
communication modes can develop every project manager involved in outsourcing into an able technical communicator.

Some of the minor limitations of our work would be about the originality of the research design, the novelty of the assertions, and even the sample size. Communications is indeed an ancient art, which has been studied from time immemorial, and this study is not a paradigm shift. It is also noted that the practice of technical communication in the project management of outsourcing is in dire need of unifying frameworks which explain the parameters and their contingencies. As Carlson \& Zmud (1999) caution, "How individuals select, use and perceive communications channels is a topic that is deceptively simple, particularly in regard to electronic mail" (p 155) ... and, one might add, generally in regard to new media channels.

A major limitation of the study is that our above claims are based on a set of research assertions that were field tested with a survey of perceptions rather than behaviors or usage patterns. However, we draw additional validation by pointing out that our findings are consistent with research on project management, $\mathrm{CMC}$, and the organizational constructs of trust and risk. There is indeed a strong link noted between attitudes and beliefs on the one hand with behavior and practice on the other. This was confirmed in the qualitative (post-survey) interviews that we carried out during the data analysis.

From the analysis of the survey results, it can also be concluded that effective technical communication has indeed a direct impact on project success and is critical to IT outsourcing projects. However, another limitation is that the study does not yet provide a synthesis of tactics for the practitioner that goes beyond conventional wisdom or common sense. There is in fact a body of tactics that may be deployed in order to promote trust and reduce risk in order to support the objectives of project delivery. Communication takes place when conversations and negotiations occur (Wenneker, Rijt, Selm, Nelissen \& Wester 2005). Communicating with a goal of achieving project success, and a conscious effort to increase trust levels is necessary for effective technical communication. We may extend out fundamental postulates to suggest that this can be achieved through a strategy linking tactic to outcome:

- A tactic to Inform to achieve Understanding mitigates information gaps and hence risks.

- A tactic to Negotiate to achieve Acceptance increases trust levels.

- A tactic to Regulate to achieve Fulfillment results in acceptance and hence, project success.

The communication platform should also serve as organizational memory, which allows for storage for future in a shared repository (Wenneker et al, 2005). Hence, an established communication tactic of informing, negotiating, and regulating drives trust in communication, conveys the intent effectively and creates an outcome of accomplishment and consideration (Hirsch, 2003) that are essential to reducing any risks and enhancing trust due to the communication. Figure 8 illustrates the synthesis of such an extended model that may be derived from the literature review as well as field survey reported in this paper. We suggest that further research is required to validate and utilize the framework in the practice of IT outsourcing. More specifically, it would be a significant contribution to CMC and IT project management research to determine the relative efficacy of the various communication modes and project activities mitigated by tactics and outcomes described above. This is our on-going research task. 


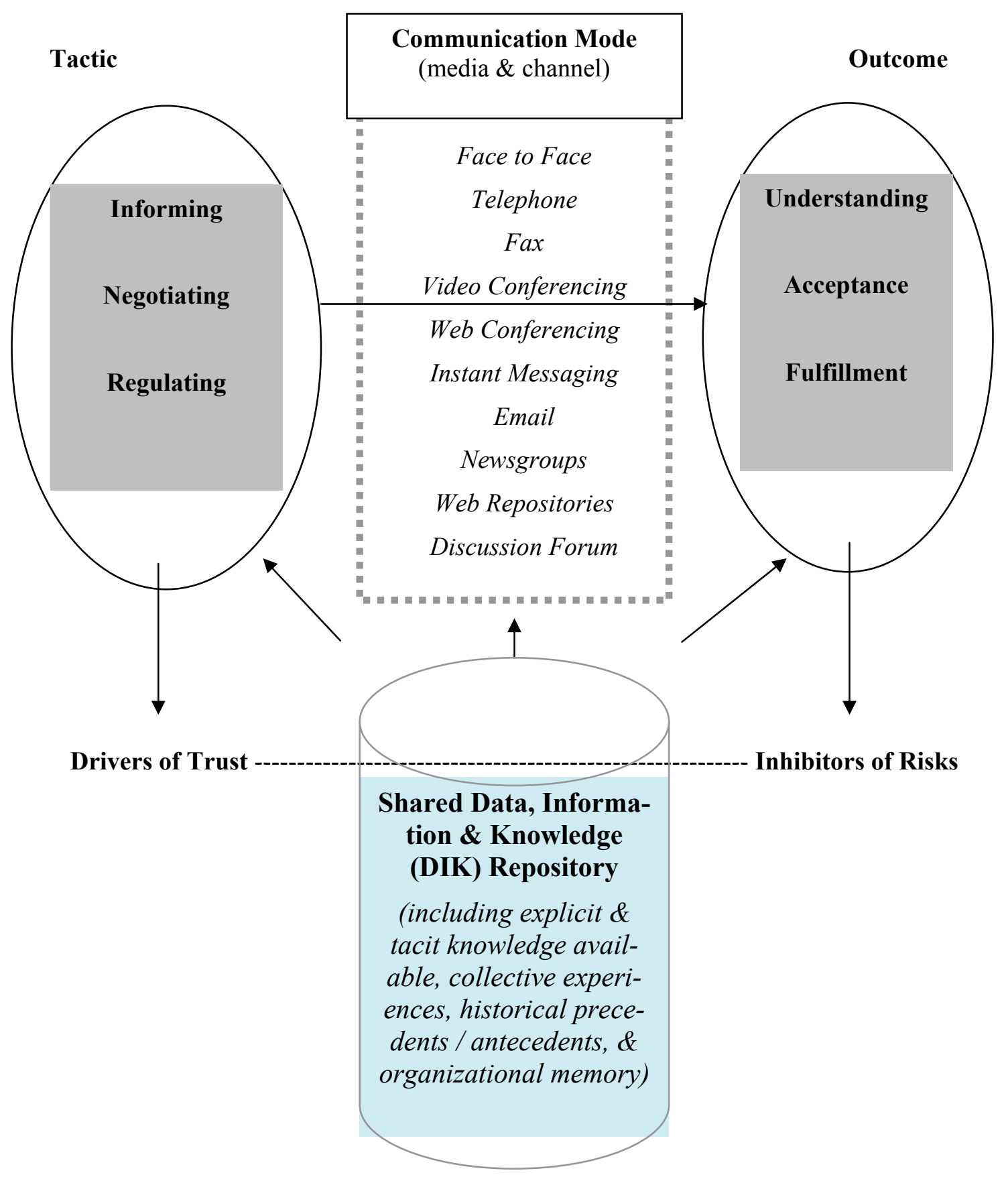

Figure 8: Extended Communications Framework for IT Outsourcing Projects 
Each of these constructs depends on the outsourcing activity involved. For example, the delivery of milestone reports would require fulfilling project commitments. This avoids information gaps by keeping every one involved aware of the developments and also increases trust and confidence on the part of the client that the vendor is indeed delivering on the specified contractual obligations. However, when the information involves technical jargon such as informing scope changes, it is important to carry out the communication with the intent of 'understanding'. Information activities may become routine or mundane and parties might lack the motivation to make efforts to effectively communicate in order to achieve an outcome. They may merely go through the motions of the communication process without accomplishing any purpose. This may lead to risks if such notions are not captured. For example, in the instance of CMC over vast distances, such behavior is difficult to identify, let alone rectify. Communication should evoke interest amongst individuals and be accounted for. The central tenet of the framework is that if appropriate tactics and platforms are used in the first place, there is a greater likelihood of achieving a desired outcome.

In order to challenge the extended framework, one could consider a situation in which there are information activities in place but no understanding, there are negotiation processes that do not lead to acceptance, and there are regulation of agreements that do not lead to fulfillment. This will most definitely lead to reduced trust levels and increased risks in the delivery of the said IT outsourcing services. If there is a situation of acceptance without understanding, (for example, service level agreements), this may affect the successful implementation of the project. Attrition of knowledge, development of organizational silos, hoarding of information, organizational politics, and competitive encroachments are some of the potential risks that may occur. If there is a situation of neither acceptance nor understanding, the technical communication can be considered to have failed. Accepted procedures may not be followed, and project activities remain unfulfilled (e.g. loss of intellectual property, occurrences of competitive encroachments, etc). This would defeat the entire purpose of the project activity. Thus, it is essential for each and every outsourcing project activity to be viewed as a step towards project success, where any element of risk or loss of trust can be harmful to the outcome.

While the risks and trust associated with the communication medium are generally understood, extracting best practices is not. Further research is needed to study the other aspects of managing technical communication processes and their resulting knowledge flows between client and vendor organizations, explicitly laying out a contingency table that includes the complexities of communications modes, multi-party relationships, culture, motivation to share and receive, absorptive capacity, and their interactions. Gupta and Govinderajan (2000) have reported interesting results in the realm of such knowledge flows within multi-national corporations. A bigger field survey would enable a deeper dive into any differences in perspective between clients and vendors, the types of outsourcing, and account for differences in culture, motivation, and absorptive capacities. It may also unearth the selective effectiveness of various communications tools and their limitations. Given the results derived from this research, it may seem reasonable to conjecture that communications mode, media, and channel play their part in project success to the extent that the tactics deployed in project communication are suited to the trust and risk contexts. No claim is made of a grand theory for project communications. The results reported in this paper merely provide a first cut at understanding the intricate relationships between project activities, communication tactics, outcomes, and platform selection. It is however a comprehensive study of $\mathrm{CMC}$, project management tactics and the twin issues of trust and risk. 


\section{References}

Adler, T. R. (2003). Member trust in teams: A synthesized analysis of contract negotiation in outsourcing work. Journal of Computer Information Systems, 64(2), 6-16.

Antonucci, Y. L., Lordi, F. C., \& Tucker, J. J. (1998). The pros and cons of IT outsourcing. Journal of Accountancy, 185(6), 26-31.

Barthelemy, J. (2001). The hidden costs of IT outsourcing. MIT Sloan Management Review, 42(3), 60-69.

Bettis, R., Bradley, S., \& Hamel, G. (1992). Outsourcing and industrial decline. Academy of Management Executive, 6(1), 7-22.

Bikson, T. K., \& Eveland, J. D. (1990). The interplay of work group structures and computer support. In J. Galegher, R. E. Kraut \& C. Egido (Eds.), Intellectual teamwork: Social and technological foundations of cooperative work (pp. 245-290). Hillsdale, NJ: Lawrence Erlbaum.

Bonk, C. J. (1998). Time to "connect": Synchronous and asynchronous case-based dialogue among preservice teachers. In C. J. Bonk \& K. S. King (Eds), Electronic collaborators: Learning Centered technologies for literacy, apprenticeship, and discourse (pp. 289-314). Mahwah, NJ: LEA.

Bos, N., Gergle, D., Olson, J. S., \& Olson, G. M. (2001). Being there versus seeing there: Trust via video. Proceedings of the Conference on Human Factors in Computing Systems (CHI '01). Seattle, Washington, pp. $291-292$.

Buchowicz, B. S. (1991). A process model of make vs. buy decision making: The case of manufacturing software. IEEE Transactions on Engineering Management, 38, 24-32.

Carliner, S., \& College, B. (1999). Knowledge management, intellectual capital, and technical communication in communication jazz: Improvising the new international communication culture. New York: IEEE Press.

Carlson, J. R., \& Zmud, R. W. (1999). Channel expansion theory and the experiential nature of media richness perceptions. Academy of Management Journal, 42(2), 153-170.

Clemons, E. K., \& Hitt, L. M. (1997). Strategic sourcing for services: Assessing the balance between outsourcing and insourcing. Discussion Draft 4.2, Wharton School of Business, University of Pennsylvania.

Collyer, M. (2000). Communication - The route to successful change management: lessons from the Guiness Integrated Business Program. Supply Chain Management: an International Journal, 5(5) 222225.

Constantinescu, R. (2005). An outsourcing model of software development. Proceedings of the 11th IEEE International Software Metrics Symposium (METRICS'05), Los Angeles, California.

Culnan, M. (1985). The dimensions of perceived accessibility to information: Implications for the delivery of information systems and services. Journal of the American Society for Information Science, 36(5), 302-308.

D'Arcy, J. (1998). Technically speaking: A guide for communicating complex information. Columbus: Battelle Press.

Daft, R. L., \& Lengel, R. H. (1986). Organizational information requirements, media richness and structural design. Management Science, 32(5), 554-571.

Daft, R., Lengel, R., \& Trevino, L. (1987). Message equivocality, media selection, and manager performance: Implications for information systems. MIS Quarterly, 11(3), 355-366.

Dibbern, J., Goles, T., Hirschheim, R., \& Jayatilaka, B. (2004). Information systems outsourcing: A survey and analysis of the literature. Database for Advances in Information Systems, 35(4), 6-102.

DiRomualdo, A., \& Gurbaxani, V. (1998). Strategic intent for IT outsourcing. Sloan Management Review, $39(4), 67-80$. 
El Shinnaway, M. (1998). The effect of medium and task on dyadic communication. IEEE Transactions on Professional Communication, 41(2), 140-142.

Elitzur, R., \& Wensley, A. (1997). Game theory as a tool for understanding information services outsourcing. Journal of Information Technology, 12, 45-60.

Finholt, T., Sproull, L., \& Kiesler, S. (1990). Communication and performance in ad hoc task groups. In J. Galegher, R. E. Kraut \& C. Egido (Eds.), Intellectual teamwork: Social and technological bases of cooperative work (pp. 291-325). Hillsdale, NJ: Lawrence Erlbaum.

Galegher, J., \& Kraut, R.E., (1990). Computer-mediated communication for intellectual teamwork: A field experiment in group writing. Proceedings of the 1990 ACM Conference on Computer-Supported Cooperative Work (CSCW '90), 65-78, October 7-10, 1990, Los Angeles, California.

Gallivan, M. J., \& Oh, W. (1999). Analyzing IT outsourcing relationships as alliances among multiple clients and vendors. HICSS-32. Proceedings of the 32nd Annual Hawaii International Conference on System Sciences, 7, pp. 15 - 24. Maui, HI.

Greenspan, S., Goldberg, D., Weimer, D. M., \& Basso, A. (2000). Interpersonal trust and common ground in electronically mediated communication. $C S C W^{\prime} 00$ Proceedings. Philadelphia: ACM Press.

Gupta, A. K., \& Govindarajan, V. (2000). Knowledge flows within multinational corporations. Strategic Management Journal, 21, 473-496.

Gurung, A., \& Prater, E. (2006). A research framework for the impact of cultural differences on IT outsourcing. Journal of Global Information Technology Management, 9(1), 24-44.

Haslett, B. (1987). Communication: Strategic action in context. Hillsdale, NJ: Lawrence Erlbaum Associates.

Hines, M. (2005). Cost-cutting drives outsourcing growth. Retrieved on October 21, 2005 from http://news.zdnet.com/2100-3513_22-5844018.html

Hirsch, H. (2003). Acquiring the successful presentation attitude. Essential communication strategies for scientists, engineers and technology professionals. New Jersey: John Wiley \& Sons.

Hofstede, G. H. (2001). Culture's consequences: Comparing values, behaviors, institutions and organizations across nations. Sage Publications through the Google Books Partner Program.

Huff, S. L. (1991). You and the computer: Outsourcing of information services. Business Quarterly, 55(4), 62-65.

Ives, M. (2005). Identifying the contextual elements of project management within organizations and their impact on project success. Project Management Institute. 36(1), 51-50.

Jennex, M. E., \& Adelakun, O. (2003). Success factors for offshore information system development. Journal of Information Technology Cases and Applications, 5(3), 12-31.

Keil, M., Cule, P. E., Lyytinen, K., \& Schmidt, R. C. (1998). A framework for identifying software project risks. Communications of the ACM, 41(11), 76-83.

Killingsworth, M. J. (1999). Technical communication in the 21st Century: Where are we going? Technical Communication Quarterly, 8(2), 165 -175.

Kraut, R. E. (1990). Informal communication in organizations: Form, function, and technology. In I. S. Oskamp \& S. Spacapan (Eds.), Human reactions to technology: The Claremont Symposium on applied social psychology. Beverly Hills, CA: Sage Publications.

Kraut, R. E., Galegher, J., \& Egido, C. (1988). Relationships and tasks in scientific collaboration. HumanComputer Interaction, 3, 31-58.

Krishna, S., Sahay, S., \& Walsham, G. (2004). Managing cross-cultural issues in global software outsourcing. Communications of the ACM, 47(4), 62-66. 
Lacity, M. C., \& Hirschheim, R. (1993). The information systems outsourcing bandwagon. Sloan Management Review, 35(1), 73-86.

Lee, M. K. O. (1996). IT outsourcing contracts: Practical issues for management. Industrial Management and Data Systems, 96(1), 15-20.

Leedy, P. O., \& Ormrod, J. E. (2005). Practical research planning and design (8th ed.). Upper Saddle River: NJ: Pearson Prentice Hall.

McCue, A. (2005, 24 June). Offshoring failures blamed on hidden costs and bad comms. Retrieved on June 27, 2005, from http://asia.cnet.com/insight/business/0,39044868,39238831,00.htm

McFarlan, F. W., \& Nolan, R. L. (1995). How to manage an IT outsourcing alliance. Sloan Management Review, 36(2), 9-23.

McGrath, J. E. (1990). Time matters in groups. In J. Galegher, R .E. Kraut \& C. Egido (Eds.), Intellectual teamwork: The social and technological foundations of cooperative work (pp. 23-61). Hillsdale, NJ: Lawrence Erlbaum.

Mullin, R. (1996). Managing the outsourced enterprise. The Journal of Business Strategy, 17(4), 29-36.

Orlikowski, W. J. (2002). Knowing in practice. Organization Science, 13(3), 255.

Oza, N., Hall, T., Rainer, A., \& Grey, S. (2005). Trust in software outsourcing relationships: An empirical investigation of Indian software companies. Proceedings of the 9th International Conference on Empirical Assessment in Software Engineering. Keele, UK.

Palvia, S., Sharma, R., \& Conrath, D. (2001). Socio-technical framework for post-implementation quality assessment of computer information systems. Industrial Management and Data Systems, 101(5), 237251.

Petrie, D. (2000a, May 22). Does outsourcing make financial cents? Accounting \& Auditing Solutions.

Petrie, D. (2000b, May 15). Outsourcing: Risky business? Accounting \& Auditing Solutions.

Pinto, J. K., \& Slevin, D. P. (1988). Critical success factors across the project life cycle. Project Management Journal, 19(3), 66-75.

Pinto, M. B., Pinto, J. K., \& Prescott, J. E. (1993). Antecedents and consequences of project team crossfunctional cooperation. Management Science, 39, 1281-1297.

Pisano, G. (1990). The R\&D boundaries of the firm: An empirical analysis. Administrative Science Quarterly, 35, 153-176.

Power, M., Bonifazi, C., \& De Souza, K. C. (2004). The ten outsourcing traps to avoid. The Journal of Business Strategy, 25(2), 37-42.

Project Management Institute. (2005). Service \& outsourcing special interest group. Retrieved on 1 October 2005 from http://www.pmi.org/prod/groups/public/documents/info/gmc_sando.asp

Richardson, I., Casey, V., Zage, D., \& Zage, W. (2005). Global software development - The challenges. Science Foundation Ireland Investigator Programme. Retrieved on December 12, 2005 from http://www.serc.net/report/tr278.pdf

Ring, P.S., \& Van de Ven, A. H. (1992). Structuring cooperative relationships between organizations. Strategic Management Journal, 13, 483-498.

Roberts, E. B., \& Berry, C. A. (1985). Entering new businesses: Selecting strategies for success. Sloan Management Review, Spring, 3-17.

Rocco, E. (1998). Trust breaks down in electronic contexts but can be repaired by some initial face-to-face contact. Proceedings of the SIGCHI conference on Human factors in computing systems, Los Angeles, California, pp. 496 - 502. 
Setlock, L., Fussel, S. R., \& Neuwirth, C. (2004). Taking it out of context: Collaborating within and across cultures in face-to-face settings and via instant messaging. Proceedings of the 2004 ACM Conference on Computer Supported Cooperative Work, Chicago, Illinois, pp. $604-613$.

Sproull, L., \& Kiesler, S. (1986). Reducing social context cues: Electronic mail in organizational communication. Management Science, 32(11), 1492-1512.

St. Amant, K. (2002). When cultures and computers collide: Rethinking computer-mediated communication according to international and intercultural communication expectations. Journal of Business and Technical Communication, 16(2), 196-214.

Sung, K., \& Young, S. C. (2003). Critical success factors for IS outsourcing implementation from an interorganizational relationship perspective. Proceedings of the 11th European Conference on Information Systems, ECIS 2003, Naples, Italy 16-21. Retrieved April 25, 2008 from http://www.informatik.unitrier.de/ ley/db/conf/ecis/ecis2003.html

Tafti, M. (2005). Risks factors associated with offshore IT outsourcing. Industrial Management and Data Systems, 105(5), $549-560$.

Turban, E., McLean, E., \& Wetherbe, J. (2002). Information technology for management: Transforming business in the digital economy (3rd ed.). New York, NY: John Wiley \& Sons.

Walther, J. B. (1997). Group and interpersonal effects in international computer mediated collaboration. Human Communication Research, 23, 342-369.

Webb, L., \& Laborde, J. (2005). Crafting a successful outsourcing vendor/client relationship. Business Process Management Journal, 11(5), 437-443.

Wenneker, M., Rijt, P., Selm, M., Nelissen, P., \& Wester, F. (2005). How does ICT support knowledge sharing. Paper presented at ICT, the Knowledge Society and Changes in Work. 1st Bi-annual European Conference. Thematic Workshop 2 "Virtual teams and virtual organizations", The Hague, June 9-10.

Yalaho, A., Nahar, N., Käkölä., T., \& Wu, C. (2002). A conceptual process framework for IT-supported international outsourcing of software production. Proceedings of the IEEE EEE05 International Workshop on Business Services Networks BSN '05. Hong Kong, pp. 3-13.

Yalaho, A. \& Wu, C. (2002). IT-supported international outsourcing of software production. Master's thesis in information systems science. University of Jyväskylä, Finland.

Zmud, R., Lind, M., \& Young, F. (1990). An attribute space for organizational communication channels. Information Systems Research, 1(4), 440-457.

\section{Biographies}

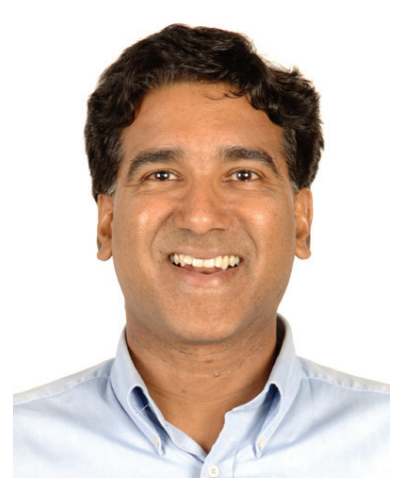

Ravi S. Sharma is Associate Professor at the Wee Kim Wee School of Communication and Information at the Nanyang Technological University. The findings reported in this article are part of the on-going efforts of an informal, irreverent group styled on the Bourbaki group of mathematicians in Paris during the 1930s. Ravi had spent the previous 10 years in industry as Asean Communications Industry Principal at IBM Global Services and Director of the Multimedia Competency Centre of Deutsche Telekom Asia. Ravi's teaching, consulting and research interests are in multimedia applications, services and strategies. He has co-authored a graduate level text on KM Tools and Techniques. He has been teaching IT and management courses since 1985 (in Canada, Singapore, Dubai, Vietnam, Indonesia and India) and enjoys this role as educator and mentor immensely. Ravi received his $\mathrm{PhD}$ in engineering from the University of Waterloo and is a Chartered Engineer (UK) and a Senior Member of the IEEE. He also sits on the editorial or advisory boards of several professional and non-profit organizations. 
Ravi gratefully acknowledges the diligence of his graduate students and the kind comments of the anonymous reviewers and JIITO EiC Bob Travica and AE Peter Trkman in seeing this study through to publication.
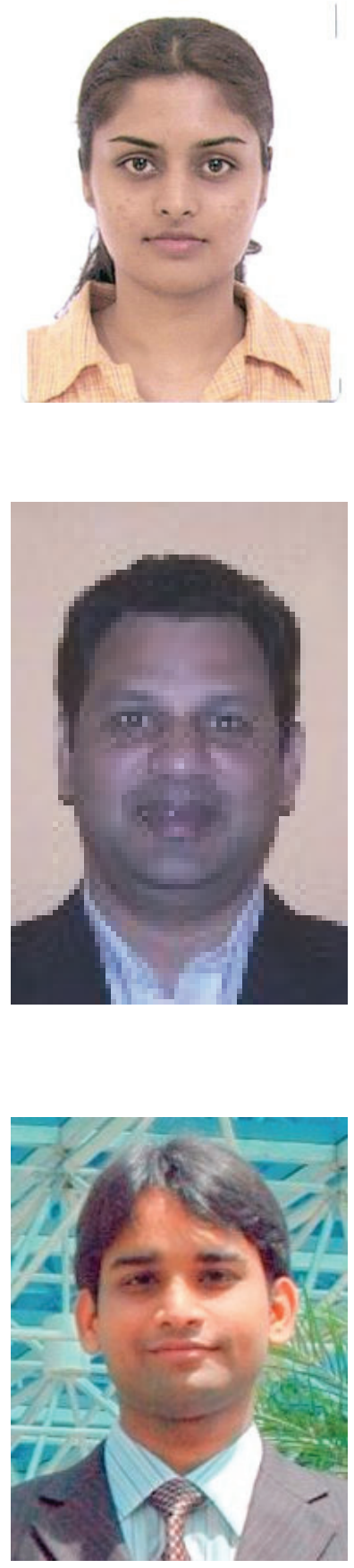

S.R. Apoorva received her MSc from the Nanyang Technological University (Singapore), majoring in Information Management. She did her dissertation work with Professor Ravi Sharma. Born and brought up in India, she came to Singapore to pursue a Computing (Information Systems) degree at the National University of Singapore. She now lives in Dallas, Texas with her family. She has accumulated useful industry experiences in handling a variety of information-products and services in the Market Research, Banking, IT and Educational industries so far, that has kindled a passion in her to be constantly placed in an information intensive environment. Apoorva's interests are in electronic document management, business intelligence and information standards \& policies.

Venkat Madireddy is a Freelance ITIL Trainer based in Singapore. He holds a Bachelors Degree in Electronics Engineering from Bangalore University, a Master of Business Administration in Operations Management from Indira Gandhi National Open University and Graduate Certificate in Project Management with Distinction from Adelaide University, Australia. Venkat has over ten years experience in the Information Technology Industry and has worked in India, Middle East, Malaysia and Singapore. He has diverse experience in Information Technology covering application development, Project Management, IT service support and service delivery. He worked with Professor Ravi Sharma as a graduate student.

Varun Jain is presently a graduate student in the knowledge management programme at the Nanyang Technological University. For his dissertation, he works with Professor Ravi Sharma on the use of web 2.0 tools for knowledge sharing. He received his BBA from DAVV (India) and worked for almost 3 years in Dubai as a Business Analyst for a US consultancy prior to this. Varun comes from a business family of India and likes writing poems and stories. He is associated with All Indian Management association and Greenpeace. 